Revista Brasil. Bot., V.32, n.2, p.375-391, abr.-jun. 2009

\title{
Fenologia reprodutiva de espécies vegetais da Floresta Ombrófila Mista do Paraná, Brasil
}

\author{
DIETER LIEBSCH ${ }^{13}$ e SANDRA BOS MIKICH ${ }^{2}$
}

(recebido: 24 de abril de 2008; aceito: 18 de março de 2009)

\begin{abstract}
Reproductive phenology of plant species of Mixed Ombrophilous Forest in Paraná, Brazil). The Mixed Ombrophilous Forest (FOM) or Araucaria Forest, vegetation that occupies regions with a highly seasonal climate subject to frost, used to cover $40 \%$ of Paraná State. Nowadays, however, there is less than $1 \%$ of advanced and well conserved FOM covering this State. This study presents the reproductive phenological patterns (flowering and fruiting) of the plant species found in FOM fragments located in three municipalities of Paraná State in order to subside restoration activities. Monthly phenological observations in 543 individuals of 145 species, representing several life forms (71 trees, 52 bushes, 18 vines and four epiphytes) were conducted between January 2004 and December 2005 employing the activity index. Flowering was recorded mainly between September and December, with a peak in October and November (68 species), followed by fruiting, which was concentrated between December and April, peaking in February (61 species). During the coldest months (June to August), the number of species with flowers or fruits was very low, with less than five species per phenophase. The availability of araucaria (Araucaria angustifolia (Bertol.) Kuntze) seeds varied between the years, but usually occurred between April and September. Significant correlations between phenophases and some abiotic factors, especially day length and temperature, were found. Therefore, plant species of the FOM proved to be highly seasonal, with periods of high and low flowering and fruiting activity, as consequence of the climatic seasonality, characteristic of the study region.
\end{abstract}

Key words - Araucaria angustifolia, Araucaria forest, flowering, fruiting, seasonal breeding

RESUMO - (Fenologia reprodutiva de espécies vegetais da Floresta Ombrófila Mista do Paraná, Brasil). A Floresta Ombrófila Mista (FOM) ou Floresta com Araucária, que ocorre em regiões de clima sazonal, com baixas temperaturas e ocorrência de geadas, cobria $40 \%$ do Estado do Paraná. Hoje, resta menos de 1\% dessa formação florestal em estádio sucessional avançado e bem conservado. O presente trabalho apresenta os padrões fenológicos reprodutivos (floração e frutificação) das espécies, presentes em fragmentos de FOM localizados em três municípios paranaenses, visando subsidiar ações de restauração. Observações fenológicas mensais em 543 indivíduos de 145 espécies, representando diferentes formas de vida (71 árvores, 52 arbustos, 18 trepadeiras e quatro epífitas), foram realizadas entre janeiro de 2004 e dezembro de 2005, utilizando o índice de atividade. A floração ocorreu principalmente nos meses de setembro a dezembro, com pico em outubro e novembro (68 espécies), e a frutificação concentrou-se entre dezembro e abril, com pico de atividade em fevereiro (61 espécies). Nos meses mais frios (junho a agosto), o número de espécies que floresceram e frutificaram foi muito baixo, com menos de cinco espécies por fenofase. A presença de sementes (pinhões) de araucária (Araucaria angustifolia (Bertol.) Kuntze) variou entre os anos, mas de modo geral ocorreu de abril a setembro. Foram encontradas correlações significativas entre as fenofases e algumas variáveis abióticas, principalmente o comprimento do dia e a temperatura. Portanto, as espécies vegetais da FOM mostramse muito sazonais, com períodos com alta e baixa atividade, tanto para a floração como para a frutificação, reflexo da sazonalidade climática, muito pronunciada na região de estudo.

Palavras-chave - Araucaria angustifolia, floração, Floresta com Araucária, frutificação, sazonalidade reprodutiva

\section{Introdução}

Fenologia é o estudo da ocorrência de eventos biológicos repetitivos e das causas de sua ocorrência em relação às forças seletivas bióticas e abióticas e a sua inter-relação entre as fases caracterizadas por estes eventos, dentro de uma ou várias espécies (Lieth 1974).

1. Remasa Reflorestadora Ltda., Rodovia PR 170 km 530, Caixa Postal 09, 84640-000 Bituruna, Paraná, Brasil.

2. Embrapa Florestas, Laboratório de Ecologia, Caixa Postal 319, 83411-000 Colombo, Paraná, Brasil.

3. Autor para correspondência: dieterliebsch@yahoo.com.br
Assim, a fenologia contribui para o entendimento da regeneração e reprodução das plantas, da organização temporal dos recursos dentro das comunidades, das interações planta-animal e da evolução da história de vida dos animais que dependem de plantas para alimentação, como herbívoros, polinizadores e dispersores (Morellato \& Leitão-Filho 1996).

Os fatores que influenciam os ritmos fenológicos podem ser divididos em duas categorias: bióticos e abióticos. Os fatores bióticos incluem adaptações morfológicas e fisiológicas, além da interação com polinizadores e dispersores (van Schaik et al. 1993, Fenner 1998). Entre 
os fatores abióticos, a precipitação, a temperatura e o comprimento do dia são considerados os mais importantes (Morellato et al. 2000).

Florestas em climas sazonais apresentam maior periodicidade em relação às fenofases, sendo a alternância entre as estações seca e úmida apontada como o principal fator envolvido no desencadeamento das mesmas (Morellato \& Leitão-Filho 1990, 1992, 1996, Morellato et al. 1989, 1990). Florestas sujeitas a sazonalidade climática menos pronunciada, como é o caso da Floresta Ombrófila Densa, apresentam sazonalidade reprodutiva menos acentuada (Morellato et al. 2000, Talora \& Morellato 2000, Marques \& Oliveira 2004), embora a floração permaneça como evento sazonal (Morellato et al. 2000).

Para a Floresta Ombrófila Mista (FOM), também conhecida como Floresta com Araucária (FA), foram publicados apenas dois estudos contemplando dados fenológicos, um realizado no Estado do Rio Grande do Sul e outro no Paraná. No primeiro, Paise \& Vieira (2005), que estudaram apenas a frutificação, constataram que a produção de frutos zoocóricos foi concentrada nos meses de verão. Já no Estado do Paraná, Marques et al. (2004) encontraram um padrão de frutificação pouco sazonal, embora o de floração tenha sido sazonal. Tal diferença no padrão sazonal da produção de frutos nas áreas de FOM estudadas por esses autores pode ser produto da variação latitudinal entre elas. De qualquer forma, fica evidente que há uma carência de estudos envolvendo a fenologia reprodutiva de espécies da FOM, principalmente se considerarmos que apenas o estudo de Marques et al. (2004) contemplou a floração e o número de espécies tratadas foi pequeno $(n<40)$ considerando a diversidade original ou mesmo atual dessa formação florestal.

A FOM pode ser definida como a mistura de floras de diferentes origens, com padrões fitofisionômicos típicos, em zona climática caracteristicamente pluvial, sem influência direta do oceano, mas com chuvas bem distribuídas ao longo do ano (Roderjan et al. 2002). A composição florística é fortemente influenciada pelas baixas temperaturas e pela ocorrência regular de geadas no inverno (Roderjan et al. 2002). Essa formação florestal correspondia a cerca de $35 \%$ da cobertura vegetal dos Estados do centro-sul do Brasil. No Paraná, onde a FOM cobria $40 \%$ do território, hoje resta menos de $1 \%$ dessa formação florestal em estádio sucessional avançado e bem conservado (Castella \& Britez 2004). Além disso, a pressão sobre ela continua por meio da extração ilegal de essências florestais e a sua substituição por outros usos da terra, como a pecuária e as florestas plantadas.

A região centro-sul do Paraná, onde foi desenvolvido o presente estudo, é apontada como área de extrema importância biológica para a conservação da biodiversidade (MMA 2000) e foi indicada por Castella et al. (2004) como uma das 25 áreas prioritárias para a conservação da FOM no Paraná, uma vez que abriga parte expressiva dos remanescentes dessa formação florestal no Estado. Dentro desta perspectiva, o presente trabalho teve como objetivos: 1) verificar a ocorrência de padrões fenológicos reprodutivos das espécies vegetais da FOM, buscando assim contribuir com o entendimento das relações florafauna, bem como com programas de conservação dessa formação florestal por meio da descrição da fenologia reprodutiva das espécies envolvidas, 2) comparar os padrões fenológicos reprodutivos entre as diversas formas de vida e síndromes de dispersão, verificando como se dá a sazonalidade entre diferentes sinúsias e tipos de dispersão de sementes e 3) relacionar as fenofases às variáveis abióticas, buscando verificar quais fatores estão mais correlacionados com os padrões fenológicos observados.

\section{Material e métodos}

Áreas de estudo - O trabalho foi desenvolvido em áreas pertencentes à Remasa Reflorestadora Ltda. (fazendas Lageado Grande e Santa Cruz) e entorno (extinto Parque Estadual das Araucárias), localizadas nos Municípios de Bituruna, General Carneiro e Palmas (26 $14-26^{\circ} 22^{\prime}$ S e $\left.51^{\circ} 34^{\prime}-51^{\circ} 39^{\prime} \mathrm{W}\right)$. A distância máxima entre as propriedades estudadas era de, no máximo, $15 \mathrm{~km}$, de tal forma que as áreas estavam sujeitas às mesmas condições climáticas. As áreas de estudo sofreram alterações em sua composição, com a retirada de espécies madeiráveis, notadamente araucária (A. angustifolia (Bertol.) Kuntze) e imbuia (Ocotea porosa (Ness \& C. Mart.) Barroso). Posteriormente, grandes extensões florestais foram substituídas por plantios comerciais de espécies exóticas, principalmente do gênero Pinus. Atualmente, tem-se um mosaico complexo de plantios florestais e florestas nativas em diversos estádios sucessionais e em diferentes graus de conservação, muitas vezes interligadas por corredores, representados principalmente pelas florestas ciliares. O clima, segundo Köppen (1948), é do tipo sub-tropical úmido mesotérmico $(\mathrm{Cfb})$ com média do mês mais quente superior a $20^{\circ} \mathrm{C}$ e do mês mais frio inferior a $18^{\circ} \mathrm{C}$, sem estação seca, verão brando e geadas severas e freqüentes (figura 1 ). Se comparadas as normais históricas (figura 1A) com os dois anos de estudo (2004 e 2005) (figura 1B), janeiro teve precipitação muito abaixo da média e outubro teve precipitação acima da média; os demais meses apresentaram valores próximos à média climática histórica. Os valores históricos apontam para a inexistência de períodos com precipitação elevada contrastando com períodos de baixa precipitação (figura 1A). As menores temperaturas são encontradas no período que vai de maio a setembro, com médias mensais inferiores a $16{ }^{\circ} \mathrm{C}$ (figura 1A). As altitudes variam entre 900 
e 1.100 m e a topografia é de fortemente ondulada a montanhosa (Maack 1981).

Método - Para o trabalho fenológico foi empregado o Método de Transecção descrito por D’Eça-Neves \& Morellato (2004), sendo utilizados cinco transecções (três na Fazenda Lageado Grande e um em cada uma das outras duas fazendas), cada qual com $5 \mathrm{~km}$ de extensão. A inclusão das espécies se deu pelo aparecimento dos indivíduos nos transectos. Todas as formas de vida (árvores, arbustos, trepadeiras e epífitas) e síndromes de dispersão (zoocóricas, anemocóricas e autocóricas) foram contempladas. No entanto, houve uma
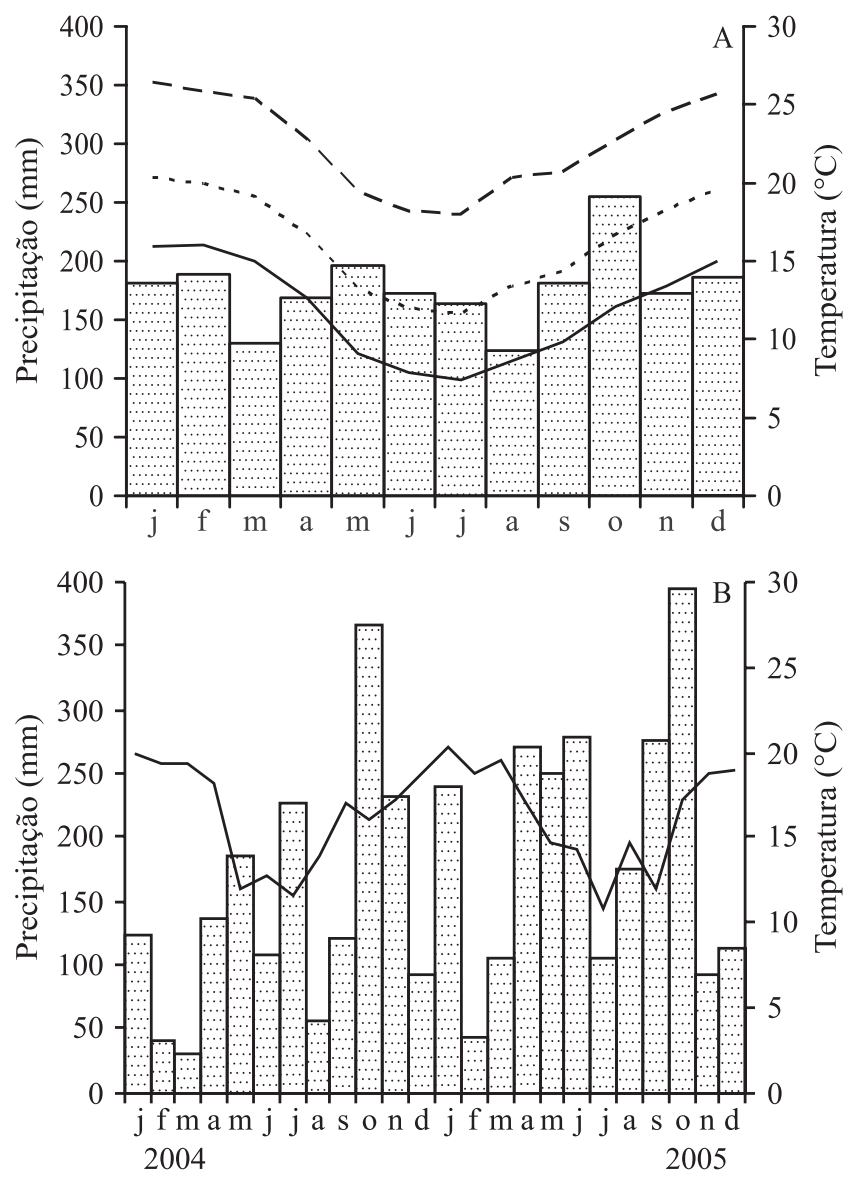

Figura 1. Clima da região de estudo: A) temperatura $(-=$ mínima; - - - = média; - - - = máxima) e precipitação média (barras) para o período de 1979-2004, no Município de PalmasPR; B) temperatura média mensal (linha) e precipitação (barras) dos anos de 2004 e 2005, no Município de PalmasPR. Fontes: (A) Simepar e (B) Iapar (2006).

Figure 1. Climate of the study region: A) temperature (- = lowest; - - - = mean and - - - = highest) and mean rainfall (bars) for the period of 1979 to 2004, in the Municipality of Palmas-PR; B) mean temperature (line) and monthly rainfall (bars) in 2004 and 2005, in the Municipality of Palmas-PR. Sources: (A) Simepar and (B) Iapar (2006). ênfase na busca de espécies zoocóricas, em função do interesse dos autores na análise da disponibilidade de recursos alimentares para espécies frugívoras. Para ser selecionado, o indivíduo deveria estar situado até $10 \mathrm{~m}$ de distância da transecção e apresentar boa visibilidade da copa. A distância mínima entre indivíduos de uma mesma espécie foi de $10 \mathrm{~m}$. Cada indivíduo selecionado foi marcado com uma fita colorida numerada e visitado mensalmente para o registro das fenofases. As seguintes fenofases foram consideradas para as angiospermas: flores em botão, flores em antese, frutos imaturos e frutos maduros. No caso de araucária $(A$. angustifolia), foi registrada a presença de pólen e de sementes maduras, cuja quantidade relativa no solo foi estimada a cada mês, utilizando-se uma escala quali-quantitativa. As espécies foram classificadas de acordo com a síndrome dispersão (van der Pijl 1972) em três categorias: zoocóricas (dispersas por animais), anemocóricas (dispersas pelo vento) e autocóricas (outro mecanismo).

O enquadramento taxonômico das espécies de Angiospermas seguiu o Angiosperm Phylogeny Group (APG II 2003). A grafia dos nomes científicos foi confirmada por meio de consultas on line ao site do banco de dados do Missouri Botanical Garden (www.tropicos.org 2008).

Para a expressão dos resultados foi adotado o índice de atividade (Bencke \& Morellato 2002), que consiste em registrar a ocorrência ou a ausência do evento reprodutivo em cada espécie. Assim, o uso do termo "pico" ao longo do texto, refere-se ao pico de atividade, definido por Bencke \& Morellato (2002) como o mês que apresenta o maior número de espécies em uma determinada fenofase. Para as variáveis climáticas foram utilizados valores médios mensais (Simepar) e históricos (no período de 1979 a 2004, IAPAR 2006) de temperatura e precipitação da estação meteorológica de Palmas-PR, situada às coordenadas 2629' S e 51 59' W, com altitude de 1.100 metros, distante $40 \mathrm{~km}$ das áreas de estudo. O comprimento do dia foi extraído de Ometto (1981).

Para verificar a existência ou não de correlação entre as fenofases (número de espécies exibindo determinada fenofase) e as variáveis climáticas (médias mensais e históricas de temperaturas, precipitação e comprimento do dia) foi utilizada a correlação de Spearman $\left(r_{s}\right)$, de acordo com Zar (1999). Seguindo Marques et al. (2004), a mesma métrica foi usada na análise do comportamento das fenofases em relação às formas de vida.

\section{Resultados}

Quantidade de espécies e indivíduos monitorados por ano - Em 2004 foram monitorados 491 indivíduos de 133 espécies, enquanto que em 2005 esses valores aumentaram para 543 indivíduos de 145 espécies. O número de espécies arbóreas monitorado foi 67 em 2004 e 71 em 2005. A segunda forma de vida com mais espécies acompanhadas foram os arbustos, com 48 espécies em 2004 e 52 em 2005. Em seguida, estão as trepadeiras, 
com 15 espécies monitoradas em 2004 e 18 em 2005. Três epífitas foram monitoradas em 2004 e em 2005 esse número subiu para quatro. Em relação às síndromes de dispersão, foram acompanhadas 114 espécies zoocóricas em 2004 e 121 em 2005. Para as espécies anemocóricas foram monitoradas 14 espécies em 2004 e 17 em 2005, enquanto para as autocóricas foram monitoradas, respectivamente, cinco e sete espécies.

Fenologia - Considerando todas as formas de vida, as espécies que compõem a FOM na região centro-sul do Estado do Paraná apresentaram alta sazonalidade fenológica nos eventos reprodutivos (figura 2; tabela 1). A formação de botões florais se deu no ano todo, porém foi mais intensa em agosto, atingindo o máximo de espécies em setembro. A floração ocorreu principalmente nos meses de setembro a dezembro, com pico em outubro e novembro (figura 2A). Os frutos imaturos foram observados o ano todo, sendo que o pico foi observado logo após a floração, nos meses de novembro e dezembro. Já o amadurecimento dos frutos ocorreu principalmente entre dezembro e abril, com pico em fevereiro (figura 2B). Nos meses mais frios (junho, julho e agosto) o número de espécies apresentando fenofases reprodutivas (floração e frutificação) foi muito baixo, com valores inferiores a $10 \%$ do total de espécies amostradas.

Fenofases - De maneira geral, as árvores, arbustos e trepadeiras apresentaram altos valores de correlação $(\geq 0,76, P<0,001)$ entre as fenofases reprodutivas (flores
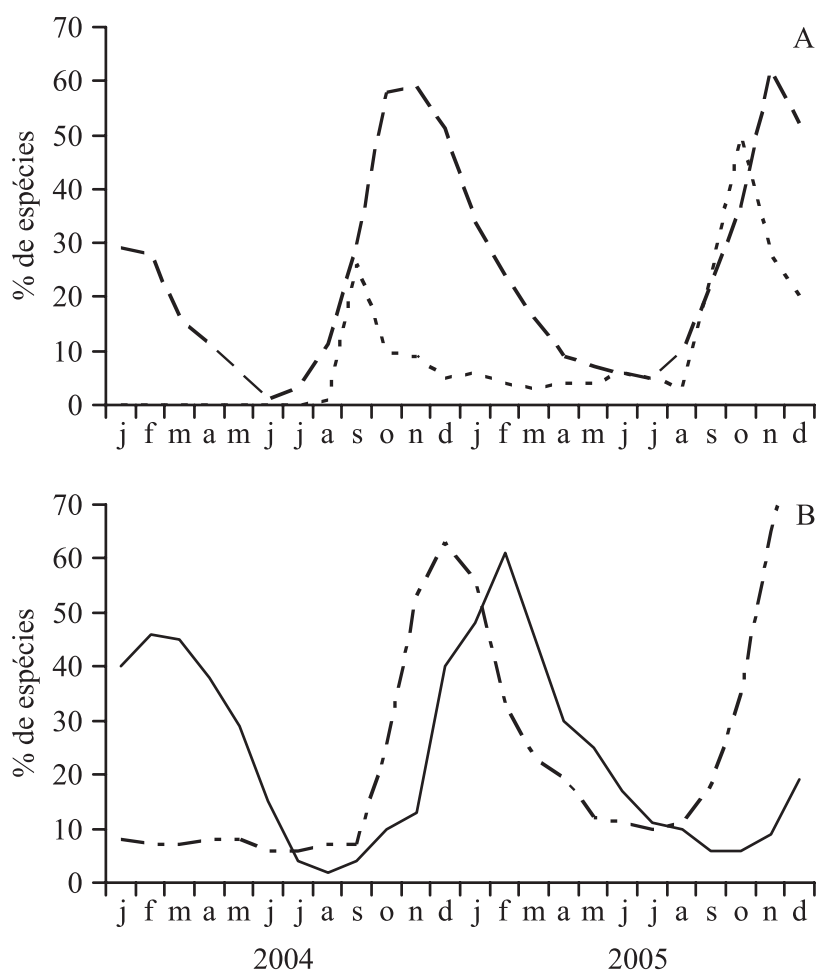

Figura 2. Floração (A) e frutificação (B) em remanescentes de Floresta Ombrófila Mista Estado do Paraná. (- - - = flores em botão; $---=$ flores em antese $;-\cdot-\cdot-=$ frutos imaturos $\mathrm{e}-=$ frutos maduros).

Figure 2. Flowering (A) and fruiting (B) in Mixed Ombrophilous Forest remnants of Paraná State. (-- = flower bud; - - - = open flower; $-\cdot-\cdot-=$ imature fruit and $-=$ mature fruit).

Tabela 1. Fenologia de espécies vegetais de três remanescentes da Floresta Ombrófila Mista localizados nos Municípios de Bituruna, General Carneiro e Palmas, Estado do Paraná, Brasil. ( $\mathrm{N}=$ número de indivíduos avaliados; $\mathrm{D}=$ síndrome de dispersão; zo = zoocórica; an = anemocórica; $\mathrm{au}=$ autocórica; $\mathrm{F}=$ forma de vida; $\mathrm{A}=$ arbórea; $\mathrm{R}=$ arbustiva; $\mathrm{T}=$ trepadeira; $\mathrm{E}=$ epifítica. Fenologia (meses do ano): $\star=$ flores em botão; $*=$ flores em antese; $\circ=$ frutos imaturos; $\bullet=$ frutos maduros).

Table 1. Phenology of plant species from three Araucaria Forest remnants located in the municipalities of Bituruna, General Carneiro and Palmas, Paraná State, Brazil. ( $\mathrm{N}=$ number of individuals studied; $\mathrm{D}=$ dispersal syndrome; zo = zoochoric; an = anemochoric; $\mathrm{au}=$ autochoric; $\mathrm{F}=$ life form; $\mathrm{A}=$ tree; $\mathrm{R}=$ bush; $\mathrm{T}=$ vine; $\mathrm{E}=$ epiphyte. Phenology (months): $\star=$ flower buds; $*=$ open flowers; $\mathrm{O}=$ imature fruit; $\bullet=$ mature fruit).

\begin{tabular}{|c|c|c|c|c|c|c|c|c|c|c|c|c|c|c|c|c|}
\hline \multirow[b]{2}{*}{ Família } & \multirow{2}{*}{ Espécie } & \multirow{2}{*}{$\mathrm{N}$} & \multirow{2}{*}{$\mathrm{D}$} & \multirow{2}{*}{$\mathrm{F}$} & \multicolumn{12}{|c|}{ Meses } \\
\hline & & & & & $\mathrm{J}$ & $\mathrm{F}$ & M & A & M & $\mathrm{J}$ & $\mathrm{J}$ & $\mathrm{A}$ & S & $\mathrm{O}$ & $\mathrm{N}$ & $\mathrm{D}$ \\
\hline Adoxaceae & $\begin{array}{l}\text { Sambucus australis Cham. \& } \\
\text { Schltdl. }\end{array}$ & 2 & Zo & A & - & & & & & & & & & & * & *o \\
\hline \multirow[t]{3}{*}{ Anacardiaceae } & Lithraea brasiliensis Marchand & 4 & Zo & A & - & & & & & & & & & $\star *$ & $\circ$ & $\circ$ \\
\hline & Schinus terebinthifolius Raddi & 6 & Zo & A & - & - & & & & & & & & $\star *$ & *o & *o \\
\hline & $\begin{array}{l}\text { Schinus polygamus (Cav.) } \\
\text { Cabrera }\end{array}$ & 3 & Zo & A & & & & & & & * & * & *o & *• & & \\
\hline Annonaceae & Rollinia emarginata Schltdl. & 3 & Zo & A & $\circ$ & $\circ$ & $\infty$ & - & & & & & & $\star *$ & *o & $\circ$ \\
\hline
\end{tabular}


continuação

\begin{tabular}{|c|c|c|c|c|c|c|c|c|c|c|c|c|c|c|c|c|}
\hline \multirow{2}{*}{ Família } & \multirow[b]{2}{*}{ Espécie } & \multirow[b]{2}{*}{$\mathrm{N}$} & \multirow[b]{2}{*}{$\mathrm{D}$} & \multirow[b]{2}{*}{$\mathrm{F}$} & \multicolumn{12}{|c|}{ Meses } \\
\hline & & & & & $\mathrm{J}$ & $\mathrm{F}$ & M & A & M & $\mathrm{J}$ & $\mathrm{J}$ & A & $\mathrm{S}$ & $\mathrm{O}$ & $\mathrm{N}$ & $\mathrm{D}$ \\
\hline \multirow[t]{4}{*}{ Aquifoliaceae } & Ilex dumosa Reissek & 3 & Zo & A & - & $\bullet$ & - & & & & & & * & $\star *$ & *o & $\circ$ \\
\hline & Ilex microdonta Reissek & 2 & Zo & A & $\circ$ & - & - & & & & & & & $\star$ & $\star$ & *o \\
\hline & Ilex paraguariensis A. St.-Hil. & 6 & Zo & A & $\infty$ & - & - & - & $\bullet$ & - & & & $\star$ & $\star *$ & *o & $\circ$ \\
\hline & Ilex theazans Mart. & 3 & Zo & A & $\circ$ & $\circ$ & $\circ$ & $\bullet$ & $\bullet$ & - & & & $\star$ & $\star$ & *o & *o \\
\hline \multirow[t]{2}{*}{ Arecaceae } & $\begin{array}{l}\text { Butia eriospatha (Mart. ex } \\
\text { Drude) Becc. }\end{array}$ & 5 & Zo & A & *o & $\circ$ & $\infty \bullet$ & $\bullet$ & - & & & & & & $\star *$ & $\star *$ \\
\hline & $\begin{array}{l}\text { Syagrus romanzoffiana (Cham.) } \\
\text { Glassman }\end{array}$ & 5 & Zo & A & & & & $\circ$ & $\circ$ & $\circ$ & $\circ$ & $\circ$ & $\circ$ & o* & $\star *$ & - \\
\hline \multirow[t]{4}{*}{ Asteraceae } & $\begin{array}{l}\text { Gochnatia polymorpha (Less.) } \\
\text { Cabrera }\end{array}$ & 7 & An & A & & & & & & & $\star$ & *o & *• & $\bullet$ & $\bullet$ & \\
\hline & $\begin{array}{l}\text { Piptocarpha angustifolia } \\
\text { Dusén ex Malme }\end{array}$ & 4 & An & A & & & & & & & * & * & * & *o & $\circ$ & - \\
\hline & $\begin{array}{l}\text { Raulinoreitzia leptophlebia } \\
\text { (B. L. Rob.) R. M. King \& } \\
\text { H. Rob. }\end{array}$ & 6 & An & A & * & * & $\bullet$ & $\bullet$ & & & & & & & & \\
\hline & $\begin{array}{l}\text { Vernonanthura discolor } \\
\text { (Spreng.) H. Rob. }\end{array}$ & 5 & An & A & & & & & * & * & * & * & * & *o & $\bullet$ & - \\
\hline \multirow[t]{3}{*}{ Bignoniaceae } & $\begin{array}{l}\text { Arrabidaea selloi (Spreng.) } \\
\text { Sandwith }\end{array}$ & 2 & An & $\mathrm{T}$ & & & & & & & & & & * & * & \\
\hline & Jacaranda puberula Cham. & 3 & An & A & $\circ$ & - & & & & & & & & * & * & $\circ$ \\
\hline & $\begin{array}{l}\text { Pithecoctenium crucigerum } \\
\text { (L.) A. H. Gentry }\end{array}$ & 3 & An & $\mathrm{T}$ & $\circ$ & $\circ$ & $\circ$ & $\circ$ & - & - & - & - & - & & $\star * ⿻ 丷 木$ & $\star * ⿻$ \\
\hline Berberidaceae & Berberis laurina Billb. & 3 & Zo & $\mathrm{R}$ & & & & & & & & $\star$ & * & *o & $\infty$ & $\infty \bullet$ \\
\hline Bromeliaceae & $\begin{array}{l}\text { Billbergia nutans } \mathrm{H} \text {. Wendl. } \\
\text { ex Regel }\end{array}$ & 3 & An & $\mathrm{E}$ & & & & & & * & * & *• & & & & \\
\hline \multirow[t]{2}{*}{ Cactaceae } & $\begin{array}{l}\text { Lepismium houlletianum } \\
\text { (Lem.) Barthlott }\end{array}$ & 3 & Zo & $\mathrm{E}$ & * & & & & & * & * & * & *o & $\star * \circ$ & $\star * 0$ & *o \\
\hline & $\begin{array}{l}\text { Rhipsalis baccifera } \\
\text { (J. S. Muell.) Stearn }\end{array}$ & 4 & Zo & $\mathrm{E}$ & $\infty$ & $\bullet$ & - & $\bullet$ & $\bullet$ & - & - & $\bullet$ & 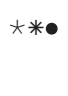 & *⿻一㇉凵 & *o & $\infty$ \\
\hline Cannabaceae & Celtis iguanaea (Jacq.) Sarg. & 3 & Zo & $\mathrm{T}$ & $\infty \bullet$ & - & - & $\bullet$ & - & & & & & * & $\circ$ & $\circ$ \\
\hline Celastraceae & $\begin{array}{l}\text { Maytenus ilicifolia (Schrad.) } \\
\text { Planch. }\end{array}$ & 2 & Zo & A & - & & & & & & & & $\star *$ & *o & $\circ$ & - \\
\hline Clethraceae & Clethra scabra Pers. & 3 & $\mathrm{Au}$ & A & *• & *⿻一㇉ & & & & & & & & & * & * \\
\hline Cunoniaceae & $\begin{array}{l}\text { Lamanonia speciosa } \\
\text { (Cambess.) L. B. Sm. }\end{array}$ & 4 & An & A & *o & $\circ$ & $\infty \bullet$ & $\bullet$ & & & & & & * & * & $\star *$ \\
\hline \multirow[t]{3}{*}{ Cucurbitaceae } & $\begin{array}{l}\text { Cayaponia biflora Cogn. ex } \\
\text { Harms }\end{array}$ & 3 & Zo & $\mathrm{T}$ & $\circ$ & - & & & & & & & & & & $\star *$ \\
\hline & Cayaponia cabocla (Vell.) Mart. & 4 & Zo & $\mathrm{T}$ & $\circ$ & $\bullet$ & & & & & & & & & & $\star *$ \\
\hline & Cayaponia tayuya (Vell.) Cogn. & 2 & Zo & $\mathrm{T}$ & & & & & & & & & & & & $\star *$ \\
\hline Elaeocarpaceae & Sloanea lasiocoma K. Schum. & 4 & An & A & - & - & & & & & & & $\star *$ & $\circ$ & $\circ$ & $\circ$ \\
\hline Erytroxylaceae & Erythroxylum myrsinites Mart. & 4 & Zo & $\mathrm{R}$ & & & & & & & & & $\star *$ & * & *o & $\bullet$ \\
\hline \multirow[t]{3}{*}{ Euphorbiaceae } & $\begin{array}{l}\text { Sebastiania commersoniana } \\
\text { (Baill.) L. B. Sm. \& Downs }\end{array}$ & 3 & $\mathrm{Au}$ & A & - & & & & & & & & & * & $\circ$ & $\circ$ \\
\hline & Sapium glandulatum (Vell.) Pax & 5 & Zo & A & $\infty \bullet$ & $\bullet$ & & & & & & & & $\star *$ & $\star *$ & $\star *$ \\
\hline & Manihot grahamii Hook. & 4 & $\mathrm{Au}$ & $\mathrm{R}$ & *o & $\circ$ & - & & & & & & & $\star *$ & * & *o \\
\hline Fabaceae & $\begin{array}{l}\text { Dalbergia frutescens (Vell.) } \\
\text { Britton }\end{array}$ & 3 & An & $\mathrm{R}$ & $\circ$ & $\circ$ & $\circ$ & $\circ$ & & & & & & & * & *⿻一未丷 \\
\hline
\end{tabular}


continuação

\begin{tabular}{|c|c|c|c|c|c|c|c|c|c|c|c|c|c|c|c|c|}
\hline \multirow{2}{*}{ Família } & \multirow{2}{*}{ Espécie } & \multirow{2}{*}{$\mathrm{N}$} & \multirow{2}{*}{$\mathrm{D}$} & \multirow{2}{*}{$\mathrm{F}$} & \multicolumn{12}{|c|}{ Meses } \\
\hline & & & & & $\mathrm{J}$ & $\mathrm{F}$ & M & A & M & $\mathrm{J}$ & $\mathrm{J}$ & A & $\mathrm{S}$ & $\mathrm{O}$ & $\mathrm{N}$ & $\mathrm{D}$ \\
\hline & Inga lentiscifolia Benth. & 4 & Zo & A & - & & & & & & & & $\star$ & *o & *o & *o \\
\hline & Mimosa scabrella Benth. & 7 & $\mathrm{Au}$ & A & - & & & & & $\star$ & * & * & *o & $\circ$ & $\circ$ & $\circ$ \\
\hline & $\begin{array}{l}\text { Senna pendula (Humb. \& } \\
\text { Bonpl. ex Willd.) H. S. Irwin } \\
\text { \& Barneby }\end{array}$ & 2 & $\mathrm{Au}$ & $\mathrm{R}$ & * & $\circ$ & & & & & & & & & & * \\
\hline Gesnericeae & $\begin{array}{l}\text { Sinningia douglasii (Lindl.) } \\
\text { Chautems }\end{array}$ & 3 & An & $\mathrm{E}$ & & & & & & & & & & * & *o & $\circ$ \\
\hline \multirow[t]{3}{*}{ Lamiaceae } & Aegiphila brachiata Velloso & 3 & Zo & A & $\circ$ & $\infty$ & - & & & & & & $\star * ⿻$ & $\star *$ & *o & $\circ$ \\
\hline & Aegiphila sellowiana Cham. & 4 & Zo & $\mathrm{R}$ & *• & - & - & - & & & & & & $\star$ & * & *o \\
\hline & $\begin{array}{l}\text { Vitex megapotamica (Spreng.) } \\
\text { Moldenke }\end{array}$ & 3 & Zo & A & $\circ$ & - & & & & & & & & $\star$ & *o & $\circ$ \\
\hline \multirow[t]{4}{*}{ Lauraceae } & Nectandra lanceolata Nees & 4 & Zo & A & $\circ$ & $\bullet$ & $\bullet$ & & & & & & * & $\star *$ & * & *o \\
\hline & Ocotea catharinensis $\mathrm{Mez}$ & 2 & Zo & A & $\infty$ & - & & & & & & & & $\star$ & $\star$ & $\circ$ \\
\hline & $\begin{array}{l}\text { Ocotea porosa (Nees \& C. } \\
\text { Mart.) Barroso }\end{array}$ & 9 & Zo & A & $\infty$ & - & - & $\bullet$ & & & & & $\star$ & $\star *$ & *o & *o \\
\hline & Ocotea puberula (Rich.) Nees & 6 & Zo & A & - & - & & & & & * & * & *o & $\circ$ & $\circ$ & $\circ$ \\
\hline Loganiaceae & $\begin{array}{l}\text { Strychnos brasiliensis } \\
\text { (Spreng.) Mart. }\end{array}$ & 3 & Zo & A & $\circ$ & $\circ$ & $\circ$ & $\circ$ & - & - & - & - & & $\star$ & * & *o \\
\hline Malpighiaceae & $\begin{array}{l}\text { Heteropteris intermedia } \\
\text { (A. Juss.) Griseb }\end{array}$ & 2 & An & $\mathrm{T}$ & * & $\circ$ & $\bullet$ & $\bullet$ & & & & & & & & \\
\hline \multirow[t]{8}{*}{ Melastomataceae } & $\begin{array}{l}\text { Leandra australis (Cham.) } \\
\text { Cogn. }\end{array}$ & 4 & Zo & $\mathrm{R}$ & *• & *• & $\bullet$ & $\bullet$ & & & & $\star$ & *o & *o & *o & *o \\
\hline & Leandra hirtella Cogn. & 3 & Zo & $\mathrm{R}$ & $\infty$ & $\infty$ & - & - & - & & & & $\star$ & $\star *$ & *o & *o \\
\hline & Leandra laevigata Cogn. & 4 & Zo & $\mathrm{R}$ & - & - & & & & & & * & $\star *$ & * & *o & $\circ$ \\
\hline & $\begin{array}{l}\text { Leandra regnellii (Triana) } \\
\text { Cogn. }\end{array}$ & 4 & Zo & $\mathrm{R}$ & *• & *• & - & $\bullet$ & & & & * & * & * & *o & *o \\
\hline & $\begin{array}{l}\text { Leandra xanthocoma (Naudin) } \\
\text { Cogn. }\end{array}$ & 3 & Zo & $\mathrm{R}$ & *o• & *• & $\bullet$ & $\bullet$ & $\bullet$ & & & & $\star$ & * & 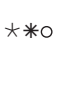 & *o \\
\hline & $\begin{array}{l}\text { Miconia hyemalis A. St.-Hil. \& } \\
\text { Naudin }\end{array}$ & 3 & Zo & $\mathrm{R}$ & & & & & & & & * & * & *o & $\bullet$ & $\bullet$ \\
\hline & Miconia cinerascens Miq. & 4 & Zo & A & $\circ$ & $\infty$ & $\bullet$ & $\bullet$ & $\bullet$ & & & & & $\star$ & $\star *$ & *o \\
\hline & $\begin{array}{l}\text { Ossea amigdalloides (DC.) } \\
\text { Triana }\end{array}$ & 2 & Zo & $\mathrm{R}$ & - & - & $\bullet$ & $\bullet$ & & & & & $\star$ & *o & *o & *⿻一㇉ \\
\hline Monimiaceae & $\begin{array}{l}\text { Mollinedia blumenaviana } \\
\text { Perkins }\end{array}$ & 3 & $\mathrm{Au}$ & $\mathrm{R}$ & & & & & & * & * & * & * & $\circ$ & $\bullet$ & \\
\hline \multirow[t]{8}{*}{ Myrtaceae } & $\begin{array}{l}\text { Acca sellowiana }(\mathrm{O} . \text { Berg) } \\
\text { Burret }\end{array}$ & 3 & Zo & A & $\circ$ & - & & & & & & & $\star$ & $\star *$ & * & $\circ$ \\
\hline & $\begin{array}{l}\text { Campomanesia guazumifolia } \\
\text { (Cambess.) O. Berg }\end{array}$ & 2 & Zo & A & & & & & & & & & & & * & *o \\
\hline & $\begin{array}{l}\text { Campomanesia xanthocarpa } \\
\text { O. Berg }\end{array}$ & 11 & Zo & A & & & & & & & & & $\star$ & $\star_{0}$ & $\infty$ & $\infty$ \\
\hline & Eugenia handroana D. Legrand & 2 & Zo & A & & & & & & & & & $\star *$ & $\star * 0$ & $\circ$ & - \\
\hline & Eugenia pyriformis Cambess. & 2 & Zo & A & *o & - & & & & & & & & $\star$ & $\star$ & * \\
\hline & Myrcia fallax (Rich.) DC. & 1 & Zo & A & & & & & & & & & & $\star$ & $\star$ & $\star * ⿻ 丷 木$ \\
\hline & Myrcia guianensis (Aubl.) DC. & 4 & Zo & A & - & & & & & & & & * & $\star * ⿻ 丷 木$ & *o & $\infty$ \\
\hline & $\begin{array}{l}\text { Myrcia hartwegiana (O. Berg) } \\
\text { Kiaersk. }\end{array}$ & 2 & Zo & A & * & & & & & & & & & & $\star$ & $\star * \circ$ \\
\hline
\end{tabular}


continuação

\begin{tabular}{|c|c|c|c|c|c|c|c|c|c|c|c|c|c|c|c|c|}
\hline \multirow{2}{*}{ Família } & \multirow{2}{*}{ Espécie } & \multirow{2}{*}{$\mathrm{N}$} & \multirow{2}{*}{$\mathrm{D}$} & \multirow{2}{*}{$\mathrm{F}$} & \multicolumn{12}{|c|}{ Meses } \\
\hline & & & & & $\mathrm{J}$ & $\mathrm{F}$ & M & A & M & $\mathrm{J}$ & $\mathrm{J}$ & A & $S$ & $\mathrm{O}$ & $\mathrm{N}$ & $\mathrm{D}$ \\
\hline & Myrcia hebepetala DC. & 2 & Zo & A & $\star$ & * & * & *o & *o & $\circ$ & $\circ$ & $\circ$ & - & - & - & $\star \bullet$ \\
\hline & $\begin{array}{l}\text { Myrceugenia alpigena (DC.) } \\
\text { Landrum }\end{array}$ & 3 & Zo & A & & & & & & & & & & $\star$ & $\star$ & $\star *$ \\
\hline & $\begin{array}{l}\text { Myrceugenia glaucescens } \\
\text { (Cambess.) D. Legrand \& } \\
\text { Kausel }\end{array}$ & 3 & Zo & A & - & & & & & & & & * & $\star *$ & *o & $\infty$ \\
\hline & $\begin{array}{l}\text { Myrceugenia ovata (Hook. \& } \\
\text { Arn.) O. Berg }\end{array}$ & 3 & Zo & A & & & & & & & & & * & * & * & * \\
\hline Onagraceae & Fuchsia regia (Vell.) Munz & 3 & Zo & $\mathrm{R}$ & * & - & & & & & & & & & & * \\
\hline \multirow[t]{2}{*}{ Myrsinaceae } & $\begin{array}{l}\text { Myrsine coriacea (Sw.) R. Br. } \\
\text { ex Roem. \& Schult. }\end{array}$ & 8 & Zo & A & $\bullet$ & $\star \bullet$ & *• & *o & $\circ$ & $\circ$ & $\circ$ & $\circ$ & $\circ$ & $\circ$ & - & $\bullet$ \\
\hline & Myrsine sp. & 4 & Zo & A & $\circ$ & - & - & - & - & - & - & $\star$ & $\star$ & *o & *o & $\infty$ \\
\hline \multirow[t]{3}{*}{ Passifloraceae } & Passiflora campanulata Mast. & 3 & Zo & $\mathrm{T}$ & & & & & & & & & & $\star$ & $\star *$ & *o \\
\hline & $\begin{array}{l}\text { Passiflora edulis f. flavicarpa } \\
\text { Deg. }\end{array}$ & 2 & Zo & $\mathrm{T}$ & $\infty$ & - & - & & & & & & * & $\star *$ & $\star_{0}$ & $\circ$ \\
\hline & Passiflora tenuifila Killip & 1 & Zo & $\mathrm{T}$ & & & & & & & & & & * & *o & *o \\
\hline Phytolacaceae & $\begin{array}{l}\text { Phytolacca thyrsiflora Fenzl } \\
\text { ex. J. A. Schmidt }\end{array}$ & 7 & Zo & $\mathrm{R}$ & *o• & *o• & *⿻一个 & *o• & *⿻一 & *o & $\infty$ & & & *o & *⿻一 & *o• \\
\hline Picramniaceae & Picramnia parvifolia Engl. & 3 & Zo & $\mathrm{R}$ & $\circ$ & - & & & & & & & & $\star$ & $\star$ & $\circ$ \\
\hline \multirow{3}{*}{ Piperaceae } & Piper gaudichaudianum Kunth & 8 & Zo & $\mathrm{R}$ & * & $\star * 0$ & $\star$ & $\star * ⿻ 丷 木$ & *o & $\star * 0$ & & *o & *o & *o & to & $\infty$ \\
\hline & $\begin{array}{l}\text { Piper mikanianum (Kunth) } \\
\text { Steud. }\end{array}$ & 7 & Zo & $\mathrm{R}$ & $\star_{0}$ & $\star * \circ$ & $\star_{0}$ & $\star_{0}$ & $\star$ & $\star_{0}$ & to & $*$ & $\star * ⿻$ & $\circ$ & to & *o \\
\hline & $\begin{array}{l}\text { Piper xylosteoides (Kunth) } \\
\text { Steud. }\end{array}$ & 6 & Zo & $\mathrm{R}$ & $\star_{0}$ & $\star_{0}$ & $\star \infty$ & $\star_{0}$ & $\star$ & * & $\star$ & $\star *$ & *o & $\star * 0$ & $\star_{0}$ & $\star_{0}$ \\
\hline Poaceae & $\begin{array}{l}\text { Merosthachys skvortzovii } \\
\text { Sendulsky }\end{array}$ & 6 & Zo & A & $\bullet$ & - & - & - & & & & & & $\star$ & $\star *$ & * \\
\hline Proteaceae & Roupala brasiliensis Klotzsch & 3 & An & A & $\circ$ & $\circ$ & & & & & & & & & & * \\
\hline Quilajaceae & $\begin{array}{l}\text { Quillaja brasiliensis } \\
\text { (A. St.-Hil. \& Tul.) Mart. }\end{array}$ & 3 & $\mathrm{Au}$ & A & * & $\circ$ & * & & & & & & & & & \\
\hline Rhamnaceae & Rhamnus sphaerosperma Sw. & 4 & Zo & A & $\bullet$ & - & - & & & & & & * & $\star *$ & *o & $\infty$ \\
\hline \multirow[t]{3}{*}{ Rosaceae } & Prunus sellowii Koehne & 9 & Zo & A & $\circ$ & $\circ$ & *o & $\circ$ & $\infty$ & $\infty$ & $\infty$ & $\infty$ & $\circ$ & *o• & *⿻一 & *o• \\
\hline & Rubus erythrocladus Mart. & 2 & Zo & $\mathrm{R}$ & *o• & *⿻一 & - & & & & & & * & *o & *o & *o• \\
\hline & $\begin{array}{l}\text { Rubus sellowii Cham. \& } \\
\text { Schltdl. }\end{array}$ & 4 & Zo & $\mathrm{R}$ & *o• & *⿻一 & *⿻一 & *⿻一 & - & • & - & & & & & \\
\hline \multirow[t]{4}{*}{ Rubiaceae } & $\begin{array}{l}\text { Alibertia concolor (Cham.) K. } \\
\text { Schum. }\end{array}$ & 2 & Zo & $\mathrm{R}$ & * & $\circ$ & $\circ$ & $\circ$ & $\circ$ & - & & & & & & \\
\hline & Palicourea australis C .M. Taylor & 3 & Zo & $\mathrm{R}$ & *o• & $\infty$ & & & & & & & & $\star$ & $\star *$ & *o \\
\hline & $\begin{array}{l}\text { Rudgea jasminoides (Cham.) } \\
\text { Müll. Arg. }\end{array}$ & 2 & Zo & $\mathrm{R}$ & $\circ$ & $\circ$ & $\circ$ & $\circ$ & $\infty$ & - & & & & $\star *$ & $\star *$ & *o \\
\hline & $\begin{array}{l}\text { Rudgea parquioides (Cham.) } \\
\text { Müll. Arg. }\end{array}$ & 4 & Zo & $\mathrm{R}$ & - & - & - & & & & & & & $\circ$ & *o & $\infty$ \\
\hline Ruscaceae & Cordyline dracaenoides Kunth & 6 & Zo & $\mathrm{R}$ & $\infty$ & $\infty$ & - & - & $\bullet$ & & & & & $\star *$ & *o & *o \\
\hline Rutaceae & Zanthoxylum rhoifolium Lam. & 5 & Zo & A & $\circ$ & - & - & & & & & & * & *o & *o & *o \\
\hline Sabiaceae & Meliosma brasiliensis Urb. & 2 & Zo & A & $\star$ & * & *o & $\circ$ & $\circ$ & $\circ$ & $\circ$ & $\circ$ & $\circ$ & $\star_{0}$ & to & ᄎo \\
\hline \multirow[t]{3}{*}{ Salicaceae } & Banara tomentosa Clos & 9 & Zo & A & & & & & & & & & & & $\star$ & $\star *$ \\
\hline & Casearia decandra Jacq. & 4 & Zo & A & - & - & & & & & & & $\star *$ & *o & * & $\circ$ \\
\hline & Xylosma brasiliensis Jacq. & 3 & Zo & A & $\bullet$ & & & & & & & & & $*$ & $\circ$ & $\bullet$ \\
\hline
\end{tabular}


continuação

\begin{tabular}{|c|c|c|c|c|c|c|c|c|c|c|c|c|c|c|c|c|}
\hline \multirow{2}{*}{ Família } & \multirow{2}{*}{ Espécie } & \multirow{2}{*}{$\mathrm{N}$} & \multirow{2}{*}{$\mathrm{D}$} & \multirow{2}{*}{$\mathrm{F}$} & \multicolumn{12}{|c|}{ Meses } \\
\hline & & & & & $\mathrm{J}$ & $\mathrm{F}$ & M & A & M & $\mathrm{J}$ & $\mathrm{J}$ & A & $\mathrm{S}$ & $\mathrm{O}$ & $\mathrm{N}$ & $\mathrm{D}$ \\
\hline Smilacaceae & Smilax campestris Griseb. & 4 & Zo & $\mathrm{T}$ & *o & $\bullet$ & - & - & $\star \bullet$ & $\star \bullet$ & $\star \bullet$ & *• & *⿻一㇉ & $\circ$ & $\circ$ & $\circ$ \\
\hline \multirow[t]{4}{*}{ Sapindaceae } & $\begin{array}{l}\text { Allophyllus edulis (A. St.-Hil.) } \\
\text { Radlk. }\end{array}$ & 6 & Zo & A & & & & & & & & & $\star *$ & *o & $\infty$ & - \\
\hline & Cupania vernalis Cambess. & 4 & Zo & A & - & * & * & *o & *o & $\circ$ & $\circ$ & $\circ$ & $\circ$ & $\circ$ & $\circ$ & $\circ$ \\
\hline & Matayba elaeagnoides Radlk. & 7 & Zo & A & - & & & & & & & & & $\star$ & * & $\circ$ \\
\hline & Serjania meridionalis Cambess. & 3 & $\mathrm{Au}$ & $\mathrm{T}$ & & * & $\circ$ & $\circ$ & - & & & & & $\star$ & & \\
\hline \multirow[t]{28}{*}{ Solanaceae } & Athenaea picta (Mart.) Sendtn. & 4 & Zo & $\mathrm{R}$ & *o• & $\infty$ & 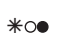 & 米戊 & 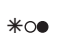 & $\infty$ & $\infty$ & & *o & *o & *o & 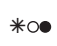 \\
\hline & Aureliana tomentosa Sendtn. & 8 & Zo & $\mathrm{R}$ & *⿻一㇉ & *⿻一㇉ & *⿻一 & *⿻一个 & *o• & $\infty$ & • & - & $\bullet$ & - & *o & *o \\
\hline & Brunfelsia pilosa Plowman & 3 & Zo & $\mathrm{R}$ & $\circ$ & $\circ$ & $\bullet$ & $\bullet$ & $\bullet$ & & & & & $\star *$ & *o & *o \\
\hline & Capsicum flexuosum Sendtn. & 5 & Zo & $\mathrm{R}$ & *⿻一㇉丶 & *⿻一 & - & - & & & & & & & $\star$ & *o \\
\hline & Cestrum intermedium Sendtn. & 3 & Zo & $\mathrm{R}$ & $\circ$ & $\infty$ & - & * & $\star *$ & $\star *$ & * & * & *o & $\infty$ & *o & $\circ$ \\
\hline & $\begin{array}{l}\text { Nicotiana langsdorffii } \\
\text { Weinmann }\end{array}$ & 2 & An & $\mathrm{R}$ & *• & & & & & & & & & * & *o & *⿻一㇉ \\
\hline & $\begin{array}{l}\text { Petunia scheideana L. B. Sm. } \\
\text { \& Downs }\end{array}$ & 2 & An & $\mathrm{T}$ & & & & & & & & & & * & *o & *o• \\
\hline & Solanum acerosum Sendtn. & 3 & Zo & $\mathrm{R}$ & *o & *⿻一 & $\infty$ & $\infty$ & - & - & - & - & - & $\star \bullet$ & * & * \\
\hline & $\begin{array}{l}\text { Solanum alternatopinatum } \\
\text { Steud. }\end{array}$ & 2 & Zo & $\mathrm{T}$ & & & & & & & & & & & * & *o \\
\hline & $\begin{array}{l}\text { Solanum bistellatum L. B. Sm. } \\
\text { \& Downs }\end{array}$ & 4 & Zo & $\mathrm{R}$ & *o & *o & $\circ$ & $\infty$ & $\bullet$ & - & & & & * & * & * \\
\hline & Solanum caeruleum Vell. & 2 & Zo & $\mathrm{R}$ & *o & *• & *• & *• & *• & & & & & * & $*$ & * \\
\hline & $\begin{array}{l}\text { Solanum cassinoides L. B. Sm. } \\
\text { \& Downs }\end{array}$ & 2 & Zo & $\mathrm{R}$ & *• & * & * & $\infty$ & *o• & *• & & $\star$ & $\star *$ & *o & *o & $\infty$ \\
\hline & $\begin{array}{l}\text { Solanum compressum L. B. Sm. } \\
\text { \& Downs }\end{array}$ & 4 & Zo & A & $\infty$ & $\infty$ & - & - & $\bullet$ & - & & & * & $\star * 0$ & *o & *⿻一㇉ \\
\hline & $\begin{array}{l}\text { Solanum corymbiflorum } \\
\text { (Sendtn.) Bohs }\end{array}$ & 3 & Zo & $\mathrm{R}$ & *o• & *⿻一 & $\infty$ & $\bullet$ & & & & & * & * & *o & *o \\
\hline & $\begin{array}{l}\text { Solanum diploconos (Mart.) } \\
\text { Bohs }\end{array}$ & 4 & Zo & $\mathrm{R}$ & $\circ$ & $\circ$ & $\circ$ & $\bullet$ & $\bullet$ & - & & & $\star * ⿻$ & $\circ$ & $\circ$ & $\circ$ \\
\hline & Solanum flaccidum Vell. & 6 & Zo & $\mathrm{T}$ & *o & *⿻一 & *• & $\bullet$ & *⿻一 & & & & & & $\star$ & $\star *$ \\
\hline & $\begin{array}{l}\text { Solanum granulosoleprosum } \\
\text { Dunal }\end{array}$ & 2 & Zo & A & $* \circ$ & *⿻一 & $\bullet$ & $\bullet$ & & & & & & * & * & *o \\
\hline & Solanum mauritianum Scop. & 5 & Zo & A & *⿻一㇉丶 & *⿻一 & *⿻一 & *• & - & $\bullet$ & & & $\star$ & * & *o & *o \\
\hline & Solanum megalochiton Mart. & 2 & Zo & $\mathrm{R}$ & & & & & & $\star *$ & * & * & *o & & & \\
\hline & Solanum тиеlleri Bitter & 3 & Zo & $\mathrm{R}$ & * & * & & & & & & & & & & \\
\hline & $\begin{array}{l}\text { Solanum pabstii L. B. Sm. \& } \\
\text { Downs }\end{array}$ & 1 & Zo & A & $\circ$ & - & - & & & & & & & $\star$ & *o & *o \\
\hline & Solanum paranense Dusén & 4 & Zo & $\mathrm{R}$ & *o• & *⿻一 & *• & $\bullet$ & $\bullet$ & $\bullet$ & * & * & * & *o & *⿻一 & *o• \\
\hline & Solanum inodorum Vell. & 5 & Zo & $\mathrm{R}$ & $* \bullet$ & **• & *o & *⿻一 & *• & $\star * \bullet$ & * & *o & *o & $\star * \bullet$ & *⿻一㇉ & *o• \\
\hline & $\begin{array}{l}\text { Solanum iraniense L. B. Sm. } \\
\text { \& Downs }\end{array}$ & 2 & Zo & $\mathrm{R}$ & & & & & & & * & * & *o & *o & *o & *o \\
\hline & $\begin{array}{l}\text { Solanum guaraniticum } \\
\text { A. St.-Hil. }\end{array}$ & 2 & Zo & $\mathrm{R}$ & & & & & & & & & & *o & $\circ$ & $\circ$ \\
\hline & Solanum lacerdae Dusén & 5 & Zo & $\mathrm{R}$ & *o & *⿻一 & *⿻一㇉ & - & & & & & * & *o & *o & *o \\
\hline & Solanum laxum Spreng. & 3 & Zo & $\mathrm{T}$ & * & $* \bullet$ & & & & & & * & * & $\star *$ & *o & *o \\
\hline & $\begin{array}{l}\text { Solanum pinetorum (L. B. Sm. } \\
\text { \& Downs) Bohs }\end{array}$ & 4 & Zo & $\mathrm{R}$ & $\circ$ & $\circ$ & - & & & & & & $\star$ & $\star *$ & $*$ & *o \\
\hline
\end{tabular}


continuação

\begin{tabular}{|c|c|c|c|c|c|c|c|c|c|c|c|c|c|c|c|c|}
\hline \multirow{2}{*}{ Família } & \multirow{2}{*}{ Espécie } & \multirow{2}{*}{$\mathrm{N}$} & \multirow{2}{*}{$\mathrm{D}$} & \multirow{2}{*}{$\mathrm{F}$} & \multicolumn{12}{|c|}{ Meses } \\
\hline & & & & & $\mathrm{J}$ & $\mathrm{F}$ & M & A & M & $\mathrm{J}$ & $\mathrm{J}$ & A & $\mathrm{S}$ & $\mathrm{O}$ & $\mathrm{N}$ & $\mathrm{D}$ \\
\hline & Solanum pseudocapsicum L. & 3 & Zo & $\mathrm{R}$ & *o• & $\infty$ & - & & & & & & $\star *$ & *o & *o & $\infty$ \\
\hline & $\begin{array}{l}\text { Solanum sanctaecatharinae } \\
\text { Dunal }\end{array}$ & 3 & Zo & A & $\infty$ & $\infty$ & - & & & & & & & $\star *$ & * & $\circ$ \\
\hline & Solanum variabile Mart. & 6 & Zo & A & *⿻一㇉ & *⿻一㇉ & $\infty$ & - & - & & & * & $\star *$ & $\star *$ & * & *o \\
\hline & Solanum viscosissimum Sendtn. & 3 & Zo & $\mathrm{T}$ & *⿻一㇉丶 & 米 & & & & & & & * & *o & *o & *⿻一㇉ \\
\hline & $\begin{array}{l}\text { Vassobia breviflora (Sendtn.) } \\
\text { Hunz. }\end{array}$ & 4 & Zo & $\mathrm{R}$ & $\bullet$ & & & & & & & & & $\star *$ & *o & *o \\
\hline \multirow[t]{2}{*}{ Styracaceae } & Styrax acuminatus Pohl & 2 & Zo & A & $\star * \bullet$ & * & *o & *o & $\circ$ & $\circ$ & $\circ$ & $\circ$ & $\circ$ & $\circ$ & $\circ$ & to \\
\hline & Styrax leprosus Hook. \& Arn. & 6 & Zo & A & *⿻一 & *o & $\circ$ & $\circ$ & $\circ$ & $\circ$ & $\circ$ & $\circ$ & $\circ$ & to & to & $\star \infty \bullet$ \\
\hline \multirow[t]{2}{*}{ Symplocaceae } & Symplocos tenuifolia Brand & 4 & Zo & A & $\circ$ & $\infty$ & - & & & & & & * & $\star$ & $\star *$ & $\circ$ \\
\hline & $\begin{array}{l}\text { Symplocos uniflora (Pohl) } \\
\text { Benth. }\end{array}$ & 3 & Zo & A & $\infty$ & - & - & & & & & & * & * & *o & $\circ$ \\
\hline Urticaceae & $\begin{array}{l}\text { Urera baccifera (L.) Gaudich. } \\
\text { ex Wedd. }\end{array}$ & 2 & Zo & $\mathrm{R}$ & * & * & *o & *• & & & & & & & * & *o \\
\hline \multirow[t]{3}{*}{ Verbenaceae } & Duranta vestita Cham. & 4 & Zo & A & $\circ$ & $\bullet$ & - & - & • & - & - & - & & & * & *o \\
\hline & Lantana camara L. & 2 & Zo & $\mathrm{R}$ & *o• & *⿻一㇉ & - & & & & & & * & *o & *⿻一 & *o• \\
\hline & Verbena lobata Vell. & 2 & Zo & $\mathrm{R}$ & & * & * & * & - & & & & * & *o & *o & $\circ$ \\
\hline Vitaceae & $\begin{array}{l}\text { Cissus verticillata } \text { (L.) } \\
\text { Nicolson \& C. E. Jarvis }\end{array}$ & 4 & Zo & $\mathrm{T}$ & *o & - & - & - & - & & & & & & $\star$ & *o \\
\hline Winteraceae & Drymis brasiliensis Miers & 4 & Zo & A & *• & *• & *⿻一㇉ & $\circ$ & $\circ$ & $\circ$ & $\circ$ & $\circ$ & $\circ$ & $\circ$ & $\circ$ & $\star \infty$ \\
\hline
\end{tabular}

em botão, flores em antese, frutos imaturos e frutos maduros) (tabela 2). Já no caso das síndromes de dispersão dos diásporos (tabela 2), espécies zoocóricas, anemocóricas e autocóricas apresentaram valores não significativos ou menos significativos para as mesmas correlações, exceto no caso da fenofase flores em botão entre anemocóricas e autocóricas e da fenofase flores em antese entre anemocóricas e zoocóricas, ambas com valores altamente significativos $(P<0,0001)$.

Fenologia das formas de vida - As espécies arbóreas floresceram principalmente entre setembro e dezembro, sendo que, no mês de novembro de 2005, 40\% das espécies desse grupo apresentavam flores em antese (figura 3A). Em relação ao número de espécies com frutos maduros, as arbóreas destacaram-se nos meses de janeiro a março, com pico em fevereiro de 2005, quando $45 \%$ das árvores apresentavam frutos nesse estágio de maturação. Já o período de junho a novembro foi marcado por uma baixa disponibilidade ou mesmo por indisponibilidade de espécies arbóreas com frutos maduros (figura 3A). As espécies arbustivas floresceram principalmente nos meses de setembro a fevereiro, com pico em outubro de 2004 e dezembro de 2005, sendo que 60\% das espécies estavam com flores abertas nesses meses (figura 3B). Ao contrário das espécies arbóreas, os arbustos apresentaram frutos maduros ao longo de todos os meses deste estudo, embora o período de julho a novembro também tenha registrado uma queda expressiva na disponibilidade desse recurso, que ficou concentrado entre dezembro e maio, com pico (49\% das espécies) em fevereiro de 2004 (figura 3B). As espécies trepadeiras apresentaram pico de floração entre outubro e janeiro, sendo que em outubro e novembro (2004) 40\% das espécies apresentavam flores abertas (figura 3C). A disponibilidade de frutos maduros dessa forma de vida foi maior nos meses de fevereiro a abril, com pico em fevereiro de 2004, quando $47 \%$ das espécies (figura 3C) estavam frutificando. Tal como nos grupos anteriores, porém, o período de junho a novembro foi marcado por uma baixa disponibilidade, ou mesmo por indisponibilidade, de frutos. As espécies epifíticas, apesar do pequeno número amostrado $(n=4)$, também pareceram concentrar a floração no final e início do ano, de outubro a janeiro; porém, não foi possível identificar algum padrão de frutificação (figura 3D).

Síndromes de dispersão - As espécies zoocóricas, como representam a maioria $(83,4 \%)$ do total de espécies amostradas, refletiram o padrão geral encontrado para a área de estudo, i.e., uma maior atividade de floração entre outubro e janeiro e uma maior atividade de frutificação dois meses depois, entre dezembro e março (figura 4). 
Tabela 2. Correlações entre formas de vida e síndromes de dispersão em relação as quatro fenofases reprodutivas de espécies de remanescentes da Floresta Ombrófila Mista do Estado do Paraná. $(*=P<0,05 ; * *=P<0,01 ; * * *=P<0,001 ; * * * *=P<0,0001$; ns $=$ não significativo).

Table 2. Correlations between life forms plus dispersal syndromes and the breeding phenophases of the plant species of Araucaria Forest remnants of Paraná State. $(*=P<0,05 ; * *=P<0,01 ; * * *=P<0,001 ; * * * *=P<0,0001$; ns $=$ not significant).

\begin{tabular}{|c|c|c|c|}
\hline $\begin{array}{l}\text { Formas de vida } \\
\text { Fenofase }\end{array}$ & Forma de vida & Trepadeiras & arbustos \\
\hline \multirow[t]{2}{*}{ Flores em botão } & árvores & $0,84 * * * *$ & $0,76^{* * * *}$ \\
\hline & arbustos & $0,77 * * * *$ & \\
\hline \multirow[t]{2}{*}{ Flores em antese } & árvores & $0,87 * * * *$ & $0,94 * * * *$ \\
\hline & arbustos & $0,88 * * * *$ & \\
\hline \multirow[t]{2}{*}{ Frutos imaturos } & árvores & $0,86 * * * *$ & $0,85 * * * *$ \\
\hline & arbustos & $0,83 * * * *$ & \\
\hline \multirow[t]{2}{*}{ Frutos maduros } & árvores & $0,64 * * *$ & $0,81 * * * *$ \\
\hline & arbustos & $0,85 * * * *$ & \\
\hline \multicolumn{4}{|c|}{ Síndrome de dispersão } \\
\hline Fenofase & Síndrome de dispersão & autocóricas & zoocóricas \\
\hline \multirow[t]{2}{*}{ Flores em botão } & anemocóricas & $0,78 * * * *$ & $0,60 * *$ \\
\hline & zoocóricas & $0,60 * *$ & \\
\hline \multirow[t]{2}{*}{ Flores em antese } & anemocóricas & $0,46 * * * *$ & $0,73 * * * *$ \\
\hline & zoocóricas & $0,61 * *$ & \\
\hline \multirow[t]{2}{*}{ Frutos imaturos } & anemocóricas & $0,67 * * *$ & ns \\
\hline & zoocóricas & $0,61 * *$ & \\
\hline \multirow[t]{2}{*}{ Frutos maduros } & anemocóricas & $\mathrm{ns}$ & ns \\
\hline & zoocóricas & $0,55^{* *}$ & \\
\hline
\end{tabular}

O período de junho a novembro, por sua vez, foi marcado por uma baixíssima disponibilidade de frutos zoocóricos, presentes em 10 ou menos espécies, que representaram, no máximo, $8 \%$ das 121 espécies avaliadas. O padrão de floração das espécies anemocóricas foi semelhante ao das zoocóricas, concentrando-se na estação úmida, entre outubro e janeiro. No caso da frutificação, porém, o padrão não foi muito evidente, provavelmente em função do pequeno número de espécies avaliadas (figura 4B). Dessa forma, em 2004, a frutificação das espécies anemocóricas exibiu um pico no outono/inverno (maio a agosto), quase seis meses após a floração, enquanto em 2005, o pico ficou quase sobreposto, concentrandose no verão (janeiro a março). As espécies autocóricas apresentaram um período de maior ocorrência de espécies com flores nos meses de agosto a janeiro, com pico em dezembro e de espécies com frutos entre dezembro e abril (figura 4C).

Formas de vida e fatores climáticos - Independente da forma de vida considerada, a presença de flores exibiu forte correlação com os fatores climáticos analisados, em particular com o comprimento do dia $\left(r_{s}=0.89, P<0,0001\right)$, embora flores em antese também tenham apresentado correlações significativas com as temperaturas históricas e do período do estudo (tabela 3). Para a presença de frutos imaturos, o comprimento do dia também foi a variável mais importante, ainda que para algumas formas de vida outros fatores abióticos também tenham contribuído com coeficientes de correlação significativos, ainda que menos expressivos. No caso de frutos maduros, no entanto, é interessante notar que o comprimento do dia foi substituído por outros fatores em termos de importância, com destaque para a temperatura (do período de estudo e histórica) no caso de árvores, que corresponderam a quase $50 \%$ do total de espécies avaliadas. A ocorrência de botões florais não se relacionou com nenhum fator abiótico de forma significativa, exceto no caso de trepadeiras, em que a precipitação do período de estudo apresentou uma fraca correlação $\left(r_{s}=0,42\right.$, $P<0,05)$ com essa fenofase.

Síndromes de dispersão e fatores abióticos - As espécies zoocóricas apresentaram correlações significativas entre 

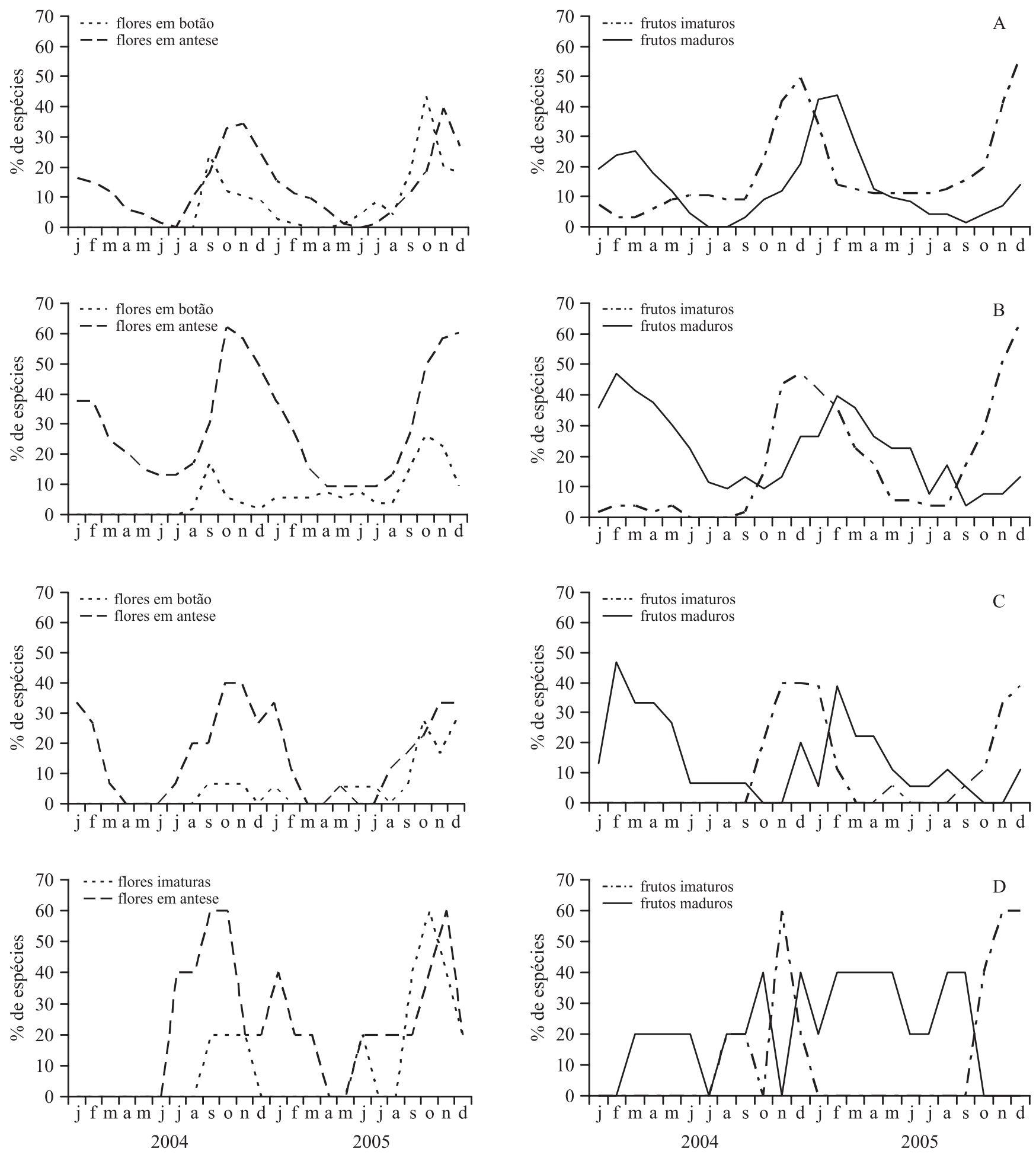

Figura 3. Floração e frutificação de espécies com diferentes formas de vida: $\mathrm{A}=$ arbóreas $(n=71)$; $\mathrm{B}=$ arbustivas $(n=52)$; $\mathrm{C}=$ trepadeiras $(n=18) ; \mathrm{D}=$ epífitas $(n=4)$ em remanescentes de Floresta Ombrófila Mista do Estado do Paraná, Brasil.

Figure 3. Patterns of flowering and fruiting of different life forms found: $\mathrm{A}=$ trees $(n=71) ; \mathrm{B}=$ bushes $(n=52)$; $\mathrm{C}=$ vines $(n=18)$; and $\mathrm{D}=$ epiphytes $(n=4)$ in Mixed Ombrophilous Forest remnants of Paraná State, Brazil. 
o comprimento do dia e espécies com flores em antese e frutos imaturos (tabela 4). A temperatura, principalmente a histórica, foi outro fator que se correlacionou significativamente com a ocorrência de flores em antese e frutos maduros. Já a precipitação, tanto histórica quanto do período de estudo, não exibiu correlação com qualquer uma das fenofases estudadas. Da mesma forma, o número de espécies com flores em botão não exibiu correlação com os fatores abióticos analisados. As espécies anemocóricas apresentaram maiores correlações com o comprimento dia para frutos imaturos e flores em antese, o segundo fator abiótico foi temperatura (histórica e do período) para frutos imaturos. Para as espécies anemocóricas, não houve correlação da precipitação com as fenofases estudadas, da mesma forma que a ocorrência de espécies com flores em botão e frutos maduros não se correlacionou com os fatores abióticos analisados. As espécies autocóricas apresentaram correlações significativas das fenofases (exceto flores em botão) com o comprimento do dia e a temperatura histórica e do período (exceto flores em antese). Não houve correlação da precipitação com as fenofases estudadas e de quaisquer fatores abióticos com o número de espécies com botões florais.
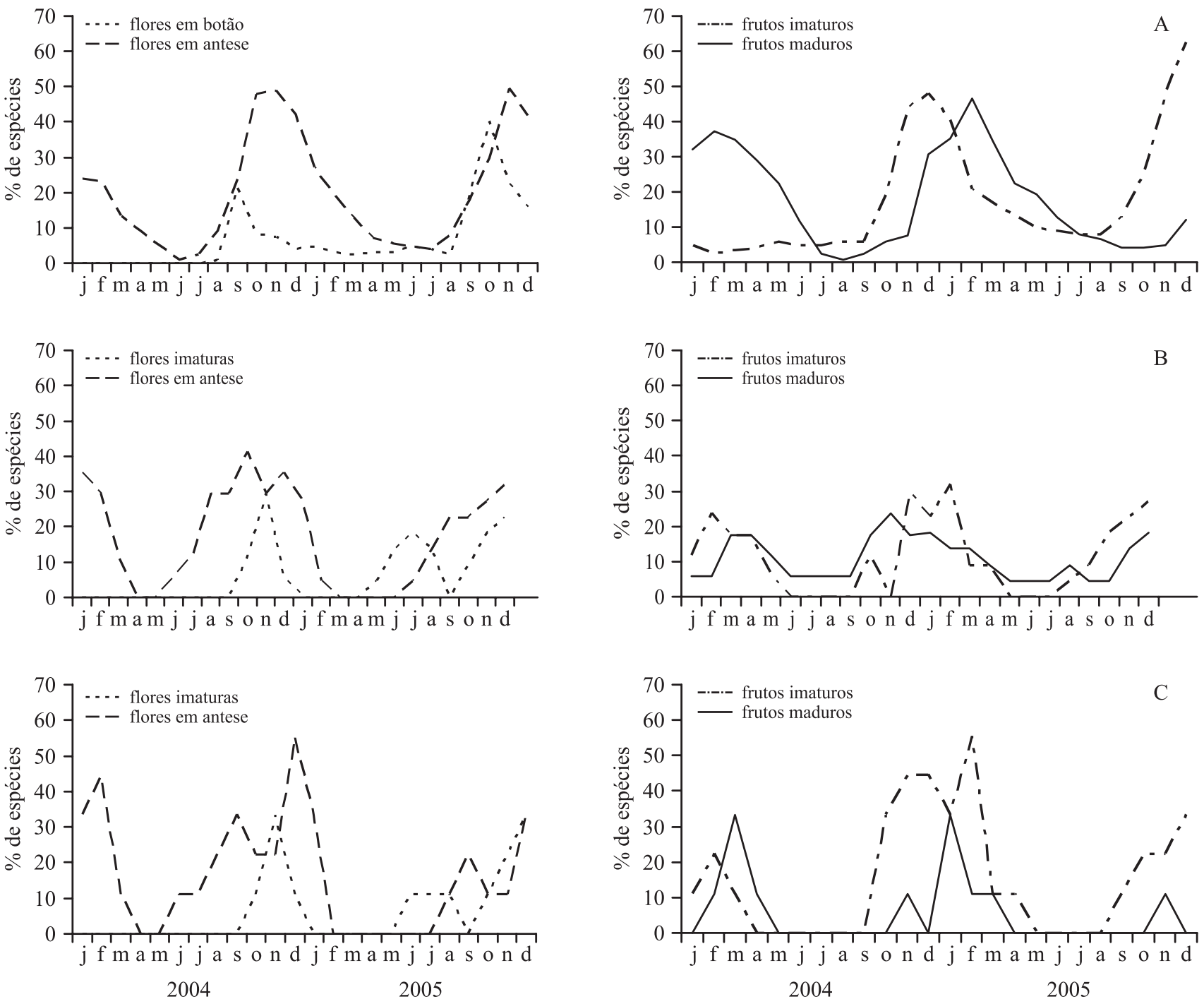

Figura 4. Floração e frutificação de espécies com diferentes síndromes de dispersão encontradas em remanescentes de Floresta Ombrófila Mista do Estado do Paraná. $(\mathrm{A}=$ zoocóricas $(n=121)$; $\mathrm{B}=$ anemocóricas $(n=16)$; e $\mathrm{C}=$ autocóricas $(n=8))$.

Figure 4. Patterns of flowering and fruiting of different dispersal syndromes found in Araucaria Forest remnants of Paraná State. $(\mathrm{A}=$ zoochoric $(n=121) ; \mathrm{B}=$ anemochoric $(n=16)$; and $\mathrm{C}=$ autochoric $(n=8))$. 
Tabela 3. Correlação de Spearman $\left(r_{s}\right)$ entre as variáveis climáticas mensais e históricas e as fenofases de diferentes formas de vida amostradas em remanescentes de Floresta Ombrófila Mista do Estado do Paraná. $(*=P<0,05 ; * *=P<0,01$; $* * *=P<0,001 ; * * * *=P<0,0001 ; \mathrm{ns}=$ não significativo. A letra " $\mathrm{h}$ " entre parêntese indica que são dados históricos).

Table 3. Spearman correlation $\left(r_{s}\right)$ between monthly and historical climatic data and the phenophases of different life forms sampled in Araucaria Forest remnants of Paraná State. $(*=P<0,05 ; * *=P<0,01 ; * * *=P<0,001 ; * * * *=P<0,0001$; $\mathrm{ns}=$ not significant. The letter " $h$ " between parenthesis indicates historical data).

\begin{tabular}{|c|c|c|c|c|c|}
\hline & Fatores abióticos & $\begin{array}{c}\text { Flores } \\
\text { em botão }\end{array}$ & $\begin{array}{c}\text { Flores } \\
\text { em antese }\end{array}$ & $\begin{array}{l}\text { Frutos } \\
\text { imaturos }\end{array}$ & $\begin{array}{c}\text { Frutos } \\
\text { maduros }\end{array}$ \\
\hline \multirow[t]{5}{*}{ Todas as espécies $(n=145)$} & Temperatura & ns & $0,58 * *$ & $\mathrm{~ns}$ & $0,68 * * *$ \\
\hline & Precipitação & ns & ns & ns & ns \\
\hline & Comprimento do dia & ns & $0,89 * * * *$ & $0,65 * * *$ & ns \\
\hline & Temperatura (h) & ns & $0,70 * * *$ & $0,48 *$ & $0,64 * * *$ \\
\hline & Precipitação (h) & ns & $\mathrm{ns}$ & ns & ns \\
\hline \multirow[t]{5}{*}{ Árvores $(n=71)$} & Temperatura & ns & $0,57 * *$ & ns & $0,81 * * * *$ \\
\hline & Precipitação & ns & ns & ns & ns \\
\hline & Comprimento do dia & ns & $0,88 * * * *$ & $0,48 *$ & $0,56 * *$ \\
\hline & Temperatura (h) & ns & $0,69 * * *$ & ns & $0,78 * * * *$ \\
\hline & Precipitação (h) & ns & ns & ns & $\mathrm{ns}$ \\
\hline \multirow[t]{5}{*}{ Arbustos $(n=52)$} & Temperatura & $\mathrm{ns}$ & $0,53 * *$ & $0,44^{*}$ & $0,57 * *$ \\
\hline & Precipitação & ns & ns & ns & ns \\
\hline & Comprimento do dia & ns & $0,86 * * * *$ & $0,66 * * *$ & $\mathrm{~ns}$ \\
\hline & Temperatura (h) & ns & $0,67 * * *$ & $0,52 * *$ & $0,48 *$ \\
\hline & Precipitação (h) & ns & $0,43 *$ & ns & $\mathrm{ns}$ \\
\hline \multirow[t]{5}{*}{ Trepadeiras $(n=18)$} & Temperatura & ns & $0,44^{*}$ & ns & $\mathrm{ns}$ \\
\hline & Precipitação & $0,42 *$ & $\mathrm{~ns}$ & ns & $0,46 *$ \\
\hline & Comprimento do dia & ns & $0,80 * * * *$ & $0,69 * * *$ & $\mathrm{~ns}$ \\
\hline & Temperatura (h) & ns & $0,58 * *$ & $0,46^{*}$ & ns \\
\hline & Precipitação (h) & ns & $\mathrm{ns}$ & $0,47 *$ & ns \\
\hline
\end{tabular}

Araucária - Em relação à disponibilidade de sementes (pinhões) de araucária, foi possível observar que houve variação de produção entre os anos, tanto em quantidade relativa de pinhões produzidos quanto no período de disponibilidade desse recurso. Em 2004 os pinhões estavam maduros no período de abril a setembro, com pico de produção nos meses de junho e julho. Já no ano de 2005 a produção também se iniciou em abril, mas terminou em julho e o pico se deu em abril e maio. Estróbilos masculinos liberaram pólen em setembro e outubro de ambos os anos avaliados.

\section{Discussão}

As 145 espécies estudadas em remanescentes da FOM no centro-sul do Estado do Paraná revelaram elevada sazonalidade reprodutiva, com períodos de alta e baixa atividade, tanto para a floração, como para a frutificação. Essa marcante sazonalidade já era esperada, pois em ambientes onde ocorre sazonalidade climática, como a encontrada para a temperatura na região de estudo, as espécies tendem a se adequar a essas condições (Morellato et al. 2000).

Em florestas tropicais sazonais, sob clima com estações seca e úmida bem definidas, a floração geralmente se dá na estação úmida ou na transição da estação seca para a úmida (Morellato \& Leitão-Filho 1990, 1992, 1996, Morellato et al. 1989, Carmo \& Morellato 2000, Oliveira \& Paula 2001, Morellato 2003), quando as primeiras chuvas e o aumento do fotoperíodo e da temperatura atuam como estímulo para o início da floração (Morellato et al. 1989). Já em florestas tropicais úmidas, a floração tende a apresentar sazonalidade menos pronunciada (Morellato et al. 2000, Talora \& Morellato 2000, San Martin-Gajardo \& Morellato 2003a, b), embora significativa com pico de floração na estação úmida relacionado ao fotoperíodo e à temperatura (Morellato et al. 2000). No caso da 
Tabela 4. Correlação de Spearman $\left(r_{s}\right)$ entre as fenofases e as variáveis climáticas mensais e históricas de acordo com as síndromes de dispersão, observadas em remanescentes de Floresta Ombrófila Mista do Estado do Paraná. $*^{*}=P<0,05$; $* *=P<0,01 ; * * *=P<0,001 ; * * * *=P<0,0001 ;$ ns = não significativo. A letra "h" entre parêntese indica que são dados históricos).

Table 4. Spearman correlation $\left(r_{s}\right)$ between phenophases of different dispersal syndromes and monthly and historic climatic variables observed in Araucaria Forest remnants of Paraná State. $(*=P<0,05 ; * *=P<0,01 ; * * *=P<0,001$; **** $=P<0,0001$; $\mathrm{ns}=$ not signifcant. The letter "h" between parenthesis indicates historical data).

\begin{tabular}{|c|c|c|c|c|c|}
\hline & Fatores abióticos & $\begin{array}{l}\text { Flores } \\
\text { em botão }\end{array}$ & $\begin{array}{c}\text { Flores } \\
\text { em antese }\end{array}$ & $\begin{array}{l}\text { Frutos } \\
\text { imaturos }\end{array}$ & $\begin{array}{l}\text { Frutos } \\
\text { maduros }\end{array}$ \\
\hline \multirow[t]{5}{*}{ Zoocoria $(n=121)$} & Temperatura & ns & $0,61 * *$ & ns & $0,66 * * *$ \\
\hline & Precipitação & ns & ns & ns & $\mathrm{ns}$ \\
\hline & Comprimento do dia & ns & $0,90 * * * *$ & $0,50 *$ & $\mathrm{~ns}$ \\
\hline & Temperatura (h) & ns & $0,72 * * * *$ & ns & $0,62 * *$ \\
\hline & Precipitação (h) & ns & ns & ns & ns \\
\hline \multirow[t]{5}{*}{ Anemocoria $(n=16)$} & Temperatura & ns & ns & $0,68 * * *$ & ns \\
\hline & Precipitação & ns & $\mathrm{ns}$ & ns & ns \\
\hline & Comprimento do dia & $\mathrm{ns}$ & $0,66 * * *$ & $0,74 * * * *$ & $\mathrm{~ns}$ \\
\hline & Temperatura (h) & ns & $0,42 *$ & $0,72 * * * *$ & ns \\
\hline & Precipitação (h) & ns & $\mathrm{ns}$ & ns & ns \\
\hline \multirow[t]{5}{*}{ Autocoria $(n=8)$} & Temperatura & ns & ns & $0,62 * *$ & $0,64 * * *$ \\
\hline & Precipitação & $\mathrm{ns}$ & $\mathrm{ns}$ & ns & $\mathrm{ns}$ \\
\hline & Comprimento do dia & $\mathrm{ns}$ & $0,63 * * *$ & $0,87 * * * *$ & $0,41 *$ \\
\hline & Temperatura (h) & ns & $0,48 *$ & $0,79 * * * *$ & $0,58^{* *}$ \\
\hline & Precipitação (h) & ns & $\mathrm{ns}$ & ns & ns \\
\hline
\end{tabular}

marcada sazonalidade da floração de espécies da FOM encontrada no presente estudo, houve uma forte correlação com a temperatura, pois esta formação florestal apresenta como fatores limitantes as baixas temperaturas e a ocorrência de geadas, que podem superar 25 eventos por ano (Castella \& Britez 2004). Por outro lado, a precipitação não se apresentou como um fator relevante para a fenologia reprodutiva das espécies desse bioma. De fato, nas áreas de estudo não foram registrados períodos de déficit hídrico e não houve correlação entre a floração e a precipitação. Assim, a correlação positiva encontrada entre o comprimento do dia e a temperatura (histórica e do período de estudo), principalmente com a floração, indica que esses fatores são determinantes na fenologia reprodutiva das espécies da Floresta com Araucária. Estes resultados, como esperado, estão de acordo com aqueles encontrados por Marques et al. (2004) em outras áreas de Floresta Ombrófila Mista, mas também são similares àqueles descritos para Floresta Ombrófila Densa por Morellato et al. (2000). No entanto diferem dos resultados encontrados em florestas semidecídas e decíduas, onde a variação da precipitação é um fator de extrema importância (Morellato \& Leitão-Filho 1990, 1992, 1996, Morellato et al. 1989, Mikich \& Silva 2001).

A disponibilidade de frutos maduros na área de estudo apresentou uma queda acentuada entre junho e novembro, quando menos de $10 \%$ das espécies estavam frutificando. Este padrão é semelhante ao encontrado na FOM do Estado do Rio Grande do Sul por Paise \& Vieira (2005). Já na Floresta Estacional Semidecidual da região centrooeste do Paraná, Mikich \& Silva (2001), trabalhando com diversas formas de vida zoocóricas, também registraram forte sazonalidade reprodutiva e encontraram um pico de frutificação entre maio e agosto, embora Carmo \& Morellato (2000), estudando espécies arbóreas e arbustivas em Floresta Semidecidual na Bacia do Rio Tibagi-PR, o tenham encontrado entre outubro e dezembro. Estudos realizados na Floresta Ombrófila Densa, por sua vez, concluíram que a frutificação é relativamente constante ao longo do ano, pois nas áreas ocupadas por essa formação florestal as condições climáticas são menos restritivas para o desenvolvimento e amadurecimento de frutos (Talora \& Morellato 2000, Morellato et al. 2000, San Martin-Gajardo \& Morellato 2003a). 
De uma maneira geral, a floração e a frutificação das espécies de diferentes formas de vida se comportam de maneira distinta nas diferentes formações florestais (Batalha \& Mantovani 2000, Spina et al. 2001, Mikich \& Silva 2001, Marques et al. 2004). Porém, no presente estudo não foi possível observar diferenças fenológicas muito pronunciadas entre as formas de vida e entre as síndromes de dispersão, em relação à floração. Essa sincronia na FOM estudada deve ter ocorrido pelo fato da floração, independente da forma de vida das espécies, se dar fora do período mais frio do ano, já que as baixas temperaturas poderiam danificar estruturas florais, além de limitar a atividade de polinizadores (Longman \& Janik 1987, Fenner 1998, Morellato et al. 2000). Embora no caso da frutificação a sincronia não seja tão acentuada, o número de espécies com frutos maduros nos meses mais frios foi muito baixo. Isso provavelmente ocorre porque o frio intenso não é favorável à germinação e ao estabelecimento (Mantovani et al. 2004, Caldato et al. 1996) e, portanto, no inverno muitas plantas devem limitar a dispersão de suas sementes.

As espécies zoocóricas frutificaram de maneira bastante sazonal, com o período de maior ocorrência de espécies em frutificação entre dezembro e março. Esse período, o mais quente do ano na região de estudo, é quando as espécies frugívoras, principalmente de aves, estão alimentando seus filhotes ou estes estão deixando os ninhos (Sick 1997) e, portanto, corresponde a um período de grande demanda de recursos alimentares. A baixíssima disponibilidade de frutos zoocóricos entre junho e novembro obriga algumas espécies a buscar recursos alternativos para a sua manutenção. É o caso do macaco-prego, Cebus nigritus, que consome seiva e floema de Pinus spp. neste período, podendo causar danos expressivos aos plantios florestais, principalmente quando a produção de pinhão é baixa (obs. pess.). Menor variação no número de espécies em frutificação ao longo do ano é descrita para Floresta Atlântica (Talora \& Morellato 2000, Morellato et al. 2000, San MartinGajardo \& Morellato 2003a, Marques \& Oliveira 2004). A frutificação das espécies anemocóricas concentrou-se entre dezembro e abril, o período um pouco mais seco do ano durante o desenvolvimento do estudo, o que deve favorecer a dispersão das suas sementes (Carmo \& Morellato 2000, Morellato \& Leitão-Filho 1992, 1996, Griz \& Machado 2001). As espécies autocóricas, embora representadas por poucas espécies, parecem não apresentar um período preferencial para o amadurecimento dos frutos, provavelmente porque não dependem de agentes bióticos ou abióticos para efetuar a dispersão, dependendo basicamente da gravidade (Morellato \& Leitão-Filho
1992). Porém, segundo Griz \& Machado (2001), a dispersão balística (autocórica) na caatinga, está relacionada às chuvas, importantes para a eficiência do processo de dispersão.

O período de disponibilidade de sementes de $A$. angustifolia pode apresentar grande variação entre os anos, assim como a duração da oferta e da quantidade de sementes (e.g. Mantovani et al. 2004, este estudo), característica observada em outras coníferas (Arista et al. 1997, Ortiz et al. 2002). No entanto, as sementes dessa espécie geralmente estão disponíveis na época mais fria do ano (Mantovani et al. 2004, Paise \& Vieira 2005), quando houve escassez de frutos na área de estudo e suas sementes revelaram-se de extrema relevância para a fauna, como já discutido por Paise \& Vieira (2005).

O presente estudo evidenciou a marcada sazonalidade reprodutiva na Floresta com Araucária, já que a quase totalidade das espécies, independente da forma de vida ou da síndrome de dispersão, floresceu em uma única estação, com a ocorrência de um período de alta disponibilidade de frutos logo após a floração e um período de extrema carência de frutos maduros nos meses mais frios. Portanto, os resultados aqui obtidos diferem daqueles já encontrados para outras áreas de Floresta Ombrófila Mista e revelam a influência de um fator climático limitante, no caso a temperatura, na fenologia reprodutiva de um conjunto amplo e diverso de espécies vegetais.

Agradecimentos - O presente trabalho fez parte do projeto "Avaliação da população e dos hábitos alimentares do macaco-prego (Cebus apella, Cebidae, Mammalia) e seu impacto em plantações comerciais de Pinus spp. e Araucaria angustifolia, para subsidiar propostas de manejo" uma parceria entre a Embrapa Florestas e a Remasa Reflorestadora Ltda. Os autores agradecem à Aline Dal'Maso pelo auxílio no trabalho de campo; à Osmar dos Santos Ribas, Gerdt Hatschbach, Rafael da Silva Possette, Marcos Sobral e Lilian Auler Mentz pelo auxílio na determinação de parte do material botânico; e à Márcia C. Marques e Valderês A. de Souza por críticas e sugestões ao manuscrito.

\section{Referências bibliográficas}

APG II. Angiosperm Phylogeny Group II. 2003. An update of the Angiosperm Phylogeny Group classification for the orders and families of flowering plants. Botanical Journal of the Linnean Society 141:399-436.

ARISTA, M., ORTIZ, P.L. \& TALAVERA, S. 1997. Reproductive isolation of two sympatric subspecies of Juniperus phoenicea (Cupressaceae) in southern Spain. Plant Systematics and Evolution 208:255-237. 
BATALHA, M.A. \& MANTOVANI, W. 2000. Reproductive phenological patterns of cerrado plant species at the Pé-de Gigante Reserve (Santa Rita do Passa Quatro, SP, Brazil): a comparation between the herbaceus and woody floras. Revista Brasileira de Biologia 60: 129-145.

BENCKE, C.S.C. \& MORELLATO, L.P.C. 2002. Comparação de dois métodos de avaliação da fenologia de plantas, sua interpretação e representação. Revista Brasileira de Botânica 25:269-275.

CALDATO, S.L., FLOSS, P.A., CROCE, D.M. da, \& LONGHI, S.J. 1996. Estudo da regeneração natural, banco de sementes e chuva de sementes na Reserva Genética Florestal de Caçador, SC. Ciência Florestal 6:27-38.

CARMO, M.R.B. do \& MORELLATO, L.P.C. 2000. Fenologia de árvores e arbustos das matas ciliares da Bacia do Rio Tibagi, estado do Paraná, Brasil. In Matas ciliares: conservação e recuperação. (R.R. Rodrigues \& H.F. Leitão Filho, orgs). Editora da Unicamp/Fapesp, Campinas, p.125-141.

CASTELLA, P.R. \& BRITEZ, R.M. 2004. A floresta com araucária no Paraná: conservação e diagnóstico dos remanescentes florestais. Fundação de Pesquisas Florestais do Paraná, Ministério do Meio Ambiente, Brasília.

CASTELLA, P.R., BRITEZ, R.M. \& MIKICH, S.B. 2004. Áreas prioritárias de Floresta com Araucária para conservação no estado do Paraná. In Anais do IV Congresso Brasileiro de Unidades de Conservação. (M.S. Milano \& V. Theulen, eds.). Fundação $\mathrm{O}$ Boticário de Proteção à Natureza, Rede Nacional Pró Unidades de Conservação, Curitiba, p.134-143.

D'EÇA-NEVES, F.F. \& MORELLATO, L.P.C. 2004. Métodos de amostragem e avaliação utilizados em estudos fenológicos de florestas tropicais. Acta Botanica Brasilica 18:99-108.

FENNER, M. 1998. The phenology of growth and reproduction in plants. Perspectives in Plant Ecology, Evolution and Systematic 1:78-91.

GRIZ, L.M.S. \& MACHADO, I.C.S. 2001. Fruiting phenology and seed dispersal syndromes in caatinga, a tropical dry forest in northeast of Brazil. Journal of Tropical Ecology 17:303-321.

IAPAR. 2006. Instituto Agronômico do Paraná. Disponibilização dos resumos históricos climáticos (dados médios), obtidos nas estações meteorológicas do Iapar. http:// www.iapar.br/sma/index.html, acesso em 08/02/2006.

LIETH, H. 1974. Introduction to phenology and the modeling of seasonality. In Phenology and seasonality modeling. (H. Lieth, ed.). Ecological Studies 8. Springer-Verlag, Berlin, p.3-19.

LONGMAN, K.A \& JANÍK, J. 1987. Tropical Forest and its environment. Longman Scientific \& Technical, New York.
KÖPPEN, W. 1948. Climatologia. Fondo de Cultura Económica. México.

MAACK, V. 1981. Geografia física do Estado do Paraná. Livraria José Olympio, Rio de Janeiro.

MMA - Ministério do Meio Ambiente. 2000. Avaliação e ações prioritárias para a conservação da biodiversidade da Mata Atlântica e Campos Sulinos. MMA/SBF, Brasília.

MANTOVANI, A., MORELLATO, L.P.C. \& REIS, M.S. 2004. Fenologia reprodutiva e produção de sementes em Araucaria angustifolia (Bert.) O. Kuntze. Revista Brasileira de Botânica 27:787-796.

MARQUES, M.C.M. \& OLIVEIRA, P.E.A.M. 2004. Fenologia de espécies do dossel e do sub-bosque de duas Florestas de Restinga na Ilha do Mel, sul do Brasil. Revista Brasileira de Botânica 27:713-723.

MARQUES, M.C.M., ROPER, J.J. \& SALVALAGGIO, A.P.B. 2004. Phenological patterns among plant lifeforms in a subtropical forest in southern Brazil. Plant Ecology 173:203-213.

MIKICH, S.B. \& SILVA, S.M. 2001. Composição florística e fenologia das espécies zoocóricas de remanescentes de Floresta Estacional Semidecidual no centro-oeste do Paraná, Brasil. Acta Botanica Brasilica 15:89-113.

MORELLATO, L.P.C. \& LEITÃO-FILHO, H.F. 1990. Estratégias fenológicas de espécies arbóreas em floresta mesófila na serra do Japi, Jundiaí, São Paulo. Revista Brasileira Biologia 50:463-173.

MORELLATO, L.P.C. \& LEITÃO-FILHO, H.F. 1992. Padrões de frutificação e dispersão na serra do Japi. In História natural da serra do Japi: ecologia e preservação de uma área florestal no sudeste do Brasil. L.P.C. (Morellato, org.). Editora da Unicamp, Campinas, p.112-140.

MORELLATO, L.P.C. \& LEITÃO-FILHO, H.F. 1996. Reprodutive phenology of climbers in a Southeasthern Brasilian Forest. Biotopica 28:180-191.

MORELLATO, L.P.C., RODRIGUES, R.R., LEITÃO-FILHO, H.F. \& JOLY, C. 1989. Estudo comparativo da fenologia de espécies arbóreas de floresta de altitude e floresta mesófila semidecídua na Serra do Japi, Jundiaí, São Paulo. Revista Brasileira de Botânica 12:85-98.

MORELLATO, L.P.C., LEITÃO-FILHO, H.F., RODRIGUES, R.R. \& JOLY, C.A. 1990. Estratégias fenológicas de espécies arbóreas em floresta de altitude na serra do Japi, Jundiaí, São Paulo. Revista Brasileira Biologia 50:149-162.

MORELLATO, L.P.C., ROMERA, E.C., TALORA, D.C., TAKAHASHI, A., BENCKE, C.C. \& ZIPPARRO, V.B. 2000. Phenology of Atlantic Rain Forest trees: a comparative study. Biotropica 32:811-823.

MORELLATO, L.P.C. 2003. Phenological data, networks, and research: South America. In Phenology: an integrative environmental science. (M.D. Schwartz, org.). Kluwer Academic Publishers, Dordrecht, p.75-92. 
OLIVEIRA, P.E.A.M. \& PAULA, F.R. 2001. Fenologia e biologia reprodutiva de plantas de matas de galeria. In Cerrado: caracterização e recuperação de matas de galeria. Embrapa-Cepac, Brasília, p.303-332.

OMETTO, J.C. 1981. Bioclimatologia vegetal. Agronômica Ceres, São Paulo.

ORTIZ, P.L., ARISTA, M. \& TALAVERA, S. 2002. Sex ratio and reprodutive effort in the dioecious Juniperus communis subsp. alpinea (Suter) Celak. (Cupressaceae) along an altitudinal gradient. Annals of Botany 89:205211.

PAISE, G. \& VIEIRA, E.M. 2005. Produção de frutos e distribuição espacial de angiospermas com frutos zoocóricos em uma Floresta Ombrófila Mista no Rio Grande do Sul. Revista Brasileira de Botânica 28: 615-625.

RODERJAN, C.V., GALVÃO, F., KUNIYOSHI, Y.S. \& HATSCHBACH, G.G. 2002. As unidades fitogeográficas do estado do Paraná, Brasil. Ciência \& Ambiente 24: 78-118.

SAN MARTIN-GAJARDO, I.S. \& MORELLATO, L.P.C. 2003a. Fenologia de espécies de Rubiaceae do subbosque em floresta Atlântica no sudeste do Brasil. Revista Brasileira de Botânica 26:299-309.
SAN MARTIN-GAJARDO, I.S. \& MORELLATO, L.P.C. 2003b. Inter and intraspecific variation on reproductive phenology of the Brazilian Atlantic forest Rubiaceae: ecology and phylogenetic constraints. Revista de Biologia Tropical 51:691-698.

SICK, H. 1997. Ornitologia Brasileira. Nova Fronteira, Rio de Janeiro.

SPINA, P.A., FERREIRA, W.M. \& LEITÃO-FILHO, H.F. 2001. Floração, frutificação e síndromes de dispersão de uma comunidade de floresta de brejo na região de Campinas (SP). Acta Botanica Brasilica 15:349-368.

TALORA, D.C. \& MORELLATO, L.P.C. 2000. Fenologia de espécies arbóreas em floresta de planície litorânea do sudeste do Brasil. Revista Brasileira de Botânica 23:13-26.

VAN DER PIJL, L. 1972. Principles of dispersal in higher plants. $2^{\text {ed. }}$ Springer-Verlag, Berlim.

VAN SCHAIK, C.P., TERBORGH, J.W. \& WRIGTH, S.J. 1993. The phenology of tropical forests: adaptative significance and consequences for primary consumers. Annual Review of Ecology and Systematics 24:353-377.

ZAR, J.H. 1999. Biostatistical analysis. Prentice-Hall, New Jersey. 